\title{
Fluid-Structure Interaction Simulation of Slam-Induced Bending in Large High-Speed Wave-Piercing Catamarans
}

\author{
Jason McVicar ${ }^{\mathrm{a}}$, Jason Lavroff ${ }^{\mathrm{b}}$, Michael R Davis ${ }^{\mathrm{b}}$, Giles Thomas ${ }^{\mathrm{c}}$ \\ ${ }^{a}$ Revolution Design Pty Ltd, Hobart, Australia \\ ${ }^{b}$ University of Tasmania, Hobart, Australia \\ ${ }^{c}$ University College London, London, UK
}

\begin{abstract}
A ship in waves may experience a water impact event known as a slam. In this paper, slam-induced bending of wave-piercing catamarans in head seas is predicted by way of fluid-structure interaction simulations. The slamming flow field during slamming of a wave-piercing catamaran is highly non-linear and cannot be accurately captured using potential flow methods as a result of the interactions between the flow fields produced by water entry of the separate demihulls and centre bow. Thus, the Reynolds-Averaged NavierStokes (RANS) equations are solved for rigid body motion of a vessel at model-scale. Verification and validation is conducted using model-scale data from a Hydroelastic Segmented Model (HSM). One-way and two-way interactions are computed considering vibration of the hull girder. In the case of one-way interactions, the computed fluid loads affect the structure, but the structural response does not affect the fluid domain solution whereas for the two-way interactions the structural response affects the fluid solution. A new method for capturing the non-linear time variation in added mass is developed and deemed necessary when computing one-way interactions, primarily as a result of the large changes in forward wetted area present for a wave-piercing catamaran. It is shown that two-way interaction simulation is not needed for predicting the slam induced hull girder loads. One-way interaction simulation can therefore be used allowing reduced computational effort.
\end{abstract}

Keywords:

Slamming, Whipping, Fluid-Structure Interaction, Hydroelasticity, 
Catamaran, Wave-piercing

\section{Introduction}

The wave-piercing catamaran configuration shown in Figure 1 includes a centre bow which provides hull volume (or reserve buoyancy) above the water line. This forward reserve buoyancy protects the vessel from deck diving [1] (immersion of the forward top deck). It also has slender forward sections in the demihulls which extend forward forming a jaw which transitions between the centre bow and demihulls. On each side of the centre bow, an arch is formed on the underside of the vessel which can fill with water given sufficient bow immersion. The geometric features specific to wave-piercing catamarans are labelled in Figure 2. These features give the wave-piercing catamaran very unique slamming (water impact) characteristics. Slams occur whenever the hull surface meets the water surface with a small acute angle and significant relative closing velocity. Slam severity depends on the relative closing velocity between the hull and water surfaces as well as the impact area. Increases in closing velocity and area both result in increased slam severity.

In the most extreme slam events of wave piercing catamarans the forward portion of the demihulls are initially dry and a bottom slam occurs first on the demihulls as they encounter the water surface. As the bow immersion increases, a bottom slam occurs on the centre bow after which immersion continues to increase. Jet flows are formed during water entry of the demihulls and centre bow with both jet flows travelling towards the top of the arch-way. While the demihull bottom slam, centre bow bottom slam and centre bow entry can each be treated separately with existing slamming models (such as the generalised Wagner model [2]), the flow fields of each hull component overlap resulting in interaction between the flow fields which limit the application of such models. Confluence of the jet flows formed on demihull and centre bow entry mark the initiation of the main slam event and are accompanied by large localised pressures at the top of the arch.

Due to the complex bow geometry associated with wave-piercing catama-

rans, very little research on slamming has been conducted using numerical methods with most prior research being conducted experimentally. Early experimental work was conducted at full scale to identify the whipping (transient vibration) response characteristics of the hull $[3,4]$ and to infer the 
slam loads from full scale data $[5,6,7,8]$. The development of hydroelastic segmented models allowed control over the encountered waves and mapping of the slamming characteristics over vessel speed, wave height and wave encounter frequency in regular seas $[9,10,11,12,13,14,15,16,17,18]$. Model-scale studies in irregular seas were also undertaken [19, 20] which allowed for the development of an empirical model [21] for the prediction of slam severity and frequency in a given sea state. Experimental drop tests have also been conducted, initially in a quasi-2D configuration [22] and in a $3 \mathrm{D}$ configuration without forward speed [23].

The primary reason for the large proportion of experimental work is that the flow field during slamming of wave piercing catamarans is three dimensional and highly non-linear, thus requiring methods which have been computationally too expensive to use given available computing resources. Figure 3 shows the slamming flow immediately following arch slam and makes evident the need to use an unsteady RANS solver if the slamming flow is to be properly captured. Prior computational work relating to Incat wave piercing catamarans has primarily focussed on vessel motions and, in particular, cases where slamming may be of low importance [24, 25, 26, 27, 28]. Much of this work stemmed from the development of a high Froude number time domain strip theory code by Holloway [24]. Direct computation of slam loads on Incat wave piercing catamarans has seen relatively little research effort with investigations so far considering two-dimensional [22, 29, 17], quasi three-dimensional (prismatic section bounded by walls) [17, 30] and threedimensional domains $[31,32,33]$. With development in available computing resources, simulation has become a more practical research tool.

One-way and two-way interaction Fluid-Structure Interaction (FSI) simulations on conventional craft are well presented in literature with various fluid and structural models ranging from potential flow solvers coupled with beam models to unsteady RANS Computational Fluid Dynamics (CFD) coupled with full finite element models [34, 35, 36, 37, 38, 39]. The most significant differences introduced by the wave-piercing catamaran geometry are the complexity of the fluid flow and the wide range of time scales in the solution [32]. The flow complexity requires an unsteady RANS equation based solver to capture the flow field interactions during arch filling and the relatively short duration of the arch slam requires a very small time step compared with the wave encounter period. An initial unsteady RANS equation based computational study of the slamming of an Incat wave piercing catamaran using the two phase Volume of Fluid (VOF) formulation $[32,33]$ found that while 
the peak slam force was under-predicted, the method captured each of the various stages of the overall slam event. Simulation will likely become more important as future interest on the slamming characteristics of wave-piercing catamarans shifts toward oblique seas. This is because the high Froude numbers which wave-piercing catamarans operate at limit the number of wave encounters which can be achieved experimentally in model test basins while simulation is not subject to such physical limits.

The large variation in bow immersion throughout the wave encounter period leads to large non-linear changes in the added mass terms which must be captured for accurate simulation. For FSI simulations allowing for two-way interactions, use of an unsteady RANS equation solver and a finite element model should be capable of simulating the transient hull response under slamming conditions. Two-way interaction inherently allows these for non-linear terms through the exchange of fluid loads and hull deformation between the fluid and structural solutions. However, the iteratively staggered coupling approach typical for two-way interactions is computationally expensive due to the fluid and structural domain solutions iteratively converging and deforming with fluid load and structural deformations being communicated at each time step. The time step must also be sufficiently small to capture the hull vibration response and the transient fluid loads. This significantly increases the computational cost for wave-piercing catamarans due to the shorter structural periods and slam transient events [32] relative to the wave encounter period.

Another consequence of the higher structural frequencies is that the hull deformations are typically small relative to the overall hull motions. Thus, the influence of the structural motion on the vessel motion and hence fluid loading is anticipated to be small. If this is the case, the complexity of two-way interaction is not necessary and only represents a convenient way of estimating the water added terms. This forms the motivation for developing a one-way interaction approach suitable for wave-piercing catamarans.

In a one-way interaction approach, the hull is considered rigid in the fluid domain. The fluid loads obtained from the fluid solution with rigid hull are applied to the structural system but the structural response does not affect the fluid loads. This eliminates the need for communication between the fluid and structural solutions along with the need to deform the fluid domain mesh and reduces the computation time. As the slamming flows for a wave-piercing catamaran are not well predicted by potential flow solvers and simplified slamming models, a one-way interaction approach suitable for 
a wave-piercing catamarans would be of benefit to reduce computational cost relative to a two-way interaction simulation. The reduction in computational cost would be of particular benefit if the approach is to be used to obtain design loads in an industry setting where simulation output is time critical and computation resources may be more limited than in a research setting. With the structural response being decoupled from the fluid flow in a oneway interaction approach, the water added mass, added damping and added hydrostatic stiffness terms are not inherently present and allowances for these terms is generally needed. When the hull immersion varies significantly, these terms will also vary significantly.

In this paper a one-way interaction method appropriate for wave-piercing catamarans is developed and presented including a new added mass model allowing for time variation in added mass. In order to allow validation of results to be conducted, simulation is conducted at model-scale in regular head seas using both the one-way and two-way interaction approaches with a hydroelastic segmented model represented in the structural domain.

One-way interaction simulations are conducted with and without time varying added mass. In the case of constant added mass, only the still water added mass is accounted for and so no added mass on the centre bow is represented. It is shown that considering time varying added mass is necessary for the one-way interaction approach to give similar bending amplitude and frequency to that of a two-way interaction simulation. Verification is conducted for the rigid simulations and validation is conducted against prior experimental results [1]. As the one-way interaction is an approach which may be attractive in an industry setting, the commercially available code Star-CCM+ is used for all fluid domain simulations and is coupled with the commercial code ABAQUS for the two-way interaction simulations. The structural response in the one-way interaction simulations is computed using a code developed in MATLAB.

Although the method is applied and tested here at model-scale, in principal there is no reason that the method cannot be applied at full-scale. The choice of an unsteady RANS solver will require a more refined mesh at full-scale, primarily to maintain the boundary layer coordinate $y^{+}$within an acceptable range for the relatively reduced boundary layer thickness associated with the higher Reynolds number flow. 


\section{Proposed One-Way Interaction Approach}

The motion amplitudes of the hull can well exceed the amplitude of the wave excitation with the motion amplitude typically reaching around 1.4 times the wave amplitude at resonance in moderate waves [16]. Thus, to accurately capture the motion of a vessel in a seaway, two-way interaction is necessary for the rigid body portion of the motion. As a result it is necessary to separate the rigid body and flexural motion of the ship for a one-way interaction approach to be implemented for a ship. This also separates the added mass, damping and stiffness terms into their rigid body components and their flexural components. This general approach has been used for conventional craft, but special treatment (particularly for the added mass terms) is necessary for application to a wave-piercing catamaran.

As the structural response does not affect the fluid domain, the structural response can either be computed in parallel with the fluid domain solution or alternatively after the fluid domain solution has been computed. The latter allows the structural response to be calculated only at critical portions of the wave loading if desired, further reducing the computational cost. For the proposed approach the structural domain solution was computed after the fluid domain solution.

By way of computing the rigid body motion with two-way interaction, the rigid body portion of the added terms is accounted for in the solution. While expansion of the fluid forcing components is not required for a CFD solution, it is useful to understand the necessary treatment of these terms in the proposed one-way interaction approach. Using $\mathbf{M}, x, F_{F K}, F_{D}, \mathbf{A}$, $\mathbf{B}$ and $\mathbf{C}$ to denote the mass matrix, hull motion vector, Froude-Krylov force, diffraction force, added mass matrix, added damping matrix, added stiffness matrix and a superscript $R$ to denote rigid body motion, the equation governing the rigid body motion is:

$$
\mathbf{M}^{R} \ddot{x}^{R}=F_{F K}^{R}+F_{D}^{R}-\mathbf{A}^{R} \ddot{x}^{R}-\mathbf{B}^{R} \dot{x}^{R}-\mathbf{C}^{R} x^{R}
$$

For the two-way interaction solution of the rigid body motion, the added mass, damping and stiffness terms are on the right hand side and are embodied in the hull pressure distribution and are non separable. However, only the rigid body motion is present in the fluid domain solution and as the added terms are dependent upon the hull motion $x$, only the rigid body contributions to these terms are accounted for. Thus, the flexural portion of the 
terms are not present in the right hand forcing term and must be separately accounted for in the proposed one-way interaction approach.

For a wave piercing catamaran, there is significant frequency separation (typically an order of magnitude) between the flexural hull response and the typical rigid body response for a typical sea condition [9] such that separation of these response components may be a suitable simplifying assumption. Integration of the CFD pressure distribution over non-overlapping patches on the hull surface allows calculation of a forcing vector to be applied to the structural domain:

$$
\left(F_{i}\right)^{R}=\int_{A_{i}} p^{R} d A
$$

Additionally using $\mathbf{D}, \mathbf{K}$ to represent the structural damping and stiffness matrices, the flexural response of the hull can be written as:

$$
(\mathbf{M}+\mathbf{A})^{F} \ddot{x}^{F}+(\mathbf{D}+\mathbf{B})^{F} \dot{x}^{F}+(\mathbf{K}+\mathbf{C})^{F} x^{F}=F^{R}
$$

As the rigid body contributions to the added terms are embedded in the forcing vector $F^{R}$ on the right hand side as negative terms, this approach results in the summation of the flexural and rigid body contributions of the added terms ensuring that they are properly allowed for.

\subsection{Estimation of the water added terms}

The added mass, damping and stiffness coefficients for the flexural portion must be estimated in order to compute the flexural response from the specified input forcing vector $F^{R}$. The hydrostatic stiffness term was considered constant as it was small compared to the structural stiffness terms when considering the hull bending modes. Its magnitude was estimated from system identification tests (Section 5) in still water and thus represented those of zero speed. The damping ratios for simulation were estimated from modelscale towing tank data obtained using the HSM [1]. As such, the damping ratios estimated were representative of the hull at forward speed in a seaway. This was deemed appropriate as Thomas [4] found that the dominant damping sources were structural in origin though work including full scale experimentation. The large variation in wetted area on the forward portion of a wave-piercing catamaran in severe seas gives rise to large changes in the water added mass terms. It may therefore be necessary to consider time variation in water added mass. In order to determine the influence of time 
varying added mass, the proposed one-way interaction was formulated with both constant and time-varying added mass terms.

Previous approaches taken to estimate the added mass terms for conventional craft range from Lewis form approximations [40] to coupling the structural solution to acoustic elements [35, 41, 42]. While coupling to acoustic elements allows for more accurate representation of the added mass terms and potential to include dependence of water added mass on frequency, the approach would be computationally expensive with the large changes in wetted area present for a wave piercing catamaran negating the reduced computation effort associated with the one-way interaction approach. Thus, a simpler method was sought.

The Lewis form approach of Piro [40] cannot be directly adopted for analysis of a wave-piercing catamaran as the wetted surface distribution in the longitudinal direction becomes as important as that in the transverse direction in the centre bow region. Ge et al. [34] recognised the importance of the longitudinal wetted length when considering the slamming of a flat wet-deck which, in head seas, would impact simultaneously across an entire section. Thus, in their potential flow solution of wet-deck impact they considered longitudinal cross-sections of the flow. Considering only the longitudinal direction is reasonable for a broad flat wet-deck, but not so for the threedimensional geometry in the vicinity of the centre bow of a wave-piercing catamaran.

To demonstrate the importance of the longitudinal wetted length take, as an example, the time instants before and after the arch filling slam event in head seas for a wave-piercing catamaran. Consider the typical cross section of a wave piercing catamaran in the vicinity of the centre bow shown in Figure 4 and let this chosen section pass through the location of initial arch filling. Prior to arch filling the arch is dry. The two demihulls and the centre bow can therefore be considered three separate hulls, each with their own added mass. If, for simplicity, we consider the von-Kármán semicircular added mass approach, the three semicircular areas marked as $A_{1}$ represent an estimate of the added mass associated with this cross section. Later in the motion and following arch filling, the entire cross section being considered is wetted and the semicircular added mass estimate based on the wetted beam is now represented by $A_{2}$. Thus, under a transverse section analysis there is a step change in added mass at the instant of arch filling. This step change in added mass may be reasonable for a two-dimensional problem. However, as the considered section coincides with the location of initial arch 
filling, analysis of a section immediately aft or forward would result in the three separate areas similar to $A_{1}$. Thus in the three-dimensional case the indicated local added mass depth $r_{1}$ would be limited by its longitudinal proximity to a non-wetted region as well as its transverse proximity to a non-wetted region.

It is proposed here that a model for estimating the water added mass in the centre bow region should consider both the longitudinal and transverse wetted surface. A simple model which meets this criteria is to extend the von-Kármán semicircular added mass model to a hemispherical model, such that the local longitudinal wetted length is also considered in the added mass estimate. Figure 5 illustrates the distribution which would be obtained during the arch slam event. The black line on the image represents the wetted perimeter on the hull. Inside this region, water added mass is estimated by performing a boolean addition of hemispheres represented by the circles drawn within the wetted perimeter. In this manner the added mass distribution accounts for both the longitudinal and transverse wetted length. For clarity, only a small proportion of the hemispheres are represented in the figure so as to allow individual hemispherical regions to be identifiable.

In order to form an added mass estimate, sample points within the wetted region can be generated. For each sample point, the hemispherical added mass radius is calculated by determining the the minimum distance between the sample point and the wetted perimeter after projection onto the $x-y$ plane. Once all sample points have been analysed, the total added mass volume is then calculated by boolean addition of the hemispheres. This threedimensional volume can then be used to integrate the water added mass and rotational inertia on each segment of the HSM or, for full-scale analysis, to be included as non-structural mass on the hull shell elements. The ABAQUS mesh was imported into the MATLAB script used for one-way interaction simulation and the element centres of this surface mesh were used as the sample points for the added mass estimate. An example of the calm water added mass distribution is shown in Figure 6. Note that the added mass is not used to compute the slamming force and the computed CFD pressure is used to load the structural domain. This is an added mass estimate which allows inclusion of the added mass effects on the flexural response.

\subsection{Time integration of the structural response with varying added mass}

While it is common to consider the modal approach when computing the structural response to improve computational efficiency, the modal approach 
assumes a time-invariant system. However, when the system is defined as the structure with water added mass, the system is time-varying and so too are the system modes. As a result, numerical integration of the structural response is adopted in this approach.

In a system with varying mass, Newton's second law gives $\sum F=\frac{d}{d t}(m v)=$ $m \dot{v}+\dot{m} v$. Thought must now be given to treatment of the $\dot{m} v$ term when considering the added mass. In the numerical CFD simulation, the rigid body contribution to the $\dot{m} v$ term is inherently accounted for in the solution due to the tight coupling of the rigid body motion to the fluid solution (see equation 1). With the structural deformation of a wave-piercing catamaran being small compared with the rigid body motions, the rigid body motion almost completely accounts for the bow immersion and the added mass changes significantly only due to the rigid body motion. The $\dot{m} v$ term is therefore a component of the extracted CFD forces and moments and must not be accounted for twice. For this reason, the $\dot{m} v$ term was not included in the structural solution of the one-way fluid-structure interaction simulation.

In general, the centres of mass of the added mass and of the hull segment do not coincide and so the segment added mass terms cannot simply be added to the structural mass. That is the wet segment masses and centres of gravity are both variable in time. To solve this problem a split mass model was used whereby the added mass terms for a given segment were treated as an external force acting on the hull. As a consequence of this approach the added mass forces are a function of the system accelerations.

An iterative approach was adopted for each time step in order to allow the added mass force and moment estimates to converge on the basis of the accelerations estimated at the previous iteration.

$$
F_{i, k}^{a}=\mathbf{M} \ddot{x}_{i, k-1}
$$

The acceleration of the first iteration $(k=0)$ of the $i^{\text {th }}$ time step $\left(\ddot{x}_{i, 0}\right)$ is estimated from the acceleration of the final iteration $(k=n)$ of the previous time step $\left(\ddot{x}_{i-1, n}\right)$.

$$
F_{i, 0}^{a}=\mathbf{M} \ddot{x}_{i-1, n}
$$

In each subsequent iteration of the $i^{\text {th }}$ time step the added mass force is calculated on the basis of the acceleration estimate from the previous iteration. The total force was then calculated as:

$$
F_{i, k}^{*}=F_{i, k}^{a}+F^{R}
$$


where $F^{R}$ is the external force calculated in the CFD simulation. Finally, the solution was under-relaxed for stability:

$$
F_{i, k}=\left(1-\alpha_{F}\right) F_{i, k-1}+\alpha_{F} F_{i, k}^{*}
$$

where $F_{i, k}$ is the total estimated force for the current iteration, $F_{i, k-1}$ is the total force from the previous iteration and $\alpha_{F}$ is the under-relaxation factor. The added mass moments were treated in an identical manner.

The Newmark- $\beta$ algorithm [43] was implemented and used for time integration. The standard Newmark- $\beta$ algorithm is a non-iterative second order accurate implicit integration scheme. The approach was made iterative by looping the computation of a time step, maintaining the same initial conditions for the time step but updating the forcing term on each iteration based on the estimated acceleration terms from the previous iteration. This modification of the scheme could be similarly applied to other integration schemes and is a special treatment of the forcing term rather than a modification to the integration method. 


\section{Two-way Interactions}

Two-way interaction simulations were conducted to allow for direct comparison to the proposed one-way interaction approach. As two-way interaction simulations using an unsteady RANS fluid solver have not been previously conducted for wave-piercing catamarans and as CFD has only recently been applied to wave-piercing catamarans [32,33], verification and validation of these two-way interaction simulations is also carried out.

Two-way interaction simulation was conducted by implicitly coupling Star-CCM+ to ABAQUS using the SIMULIA Co-simulation engine in an iteratively staggered coupling regime. Thus, the fluid loads and structural deformation were exchanged at each iteration of the time step. Both the global rigid body hull motion and the hull flexural motion were solved in ABAQUS.

The wide range of time scales present for a wave-piercing catamaran presented issues of numerical stiffness requiring careful selection of solver parameters to address artificial added mass effects [44], in particular, underrelaxation was applied to the structural deformations imported from ABAQUS. Convergence of the coupled solution was monitored through the motion residual as well as the segment force residuals to ensure convergence.

A hull surface mesh was created in ABAQUS consisting of approximately 20,000 elements. The segments of the HSM were modelled as rigid and connected with kinematic constraints. This allowed rotation about the centres of the segment links to be modelled with rotational stiffness. As grid correspondence was not imposed, the fluid load was interpolated and mapped to the structural domain. Both Star-CCM+ and ABAQUS have built in mappers which can be used to apply the pressure loading to the finite element model. 


\section{Fluid Domain}

The fluid domain is represented by solving the unsteady RANS equations using Star-CCM+. A segregated flow solver was used, for which co-located variables are used with Rhie-and-Chow-type pressure-velocity coupling and a SIMPLE-type algorithm [45]. The multiphase flow is captured using the VOF approach which is an interface-capturing approach for free surface representation. The High Resolution Interface Capturing (HRIC) scheme [46] is implemented to ensure a sharp interface and requires that Courant numbers at the free surface be strictly controlled to prevent smearing of the water and air phases at their interface. Use of an unstructured grid allowed tight control over the mesh generation and local refinements required in the vicinity of the centre bow and free surface. The volumes were hex-dominant and prism layers on the hull surfaces were used to control the thickness of the near wall layer.

The domain size and boundary conditions were selected on the basis of the International Towing Tank Conference (ITTC) recommended procedures and guidelines [47]. The typical simulation domain boundaries are shown in Figure 7, where $L_{O A}$ is the vessel overall length and $B L$ is the vessel base line. The main exception to the ITTC recommendations was the location of the lower boundary which was placed $1.5 \mathrm{~m}$ below the free surface corresponding to the depth of the towing tank used in the model-scale experiments conducted by Lavroff [1]. As head seas were considered, a vertical, longitudinal symmetry plane was used to halve the computational domain and reduce computational requirements in terms of both memory usage and processor time. The downstream boundary was located at least $2.5 L_{O A}$ downstream of the transom and specified as a pressure outlet and the remaining 4 sides were specified as velocity inlets. While the ITTC guidelines [47] recommend the outlet to be $3-5 L_{p p}$ downstream, reducing this to $2.5 L_{p p}$ was found to have a minimal effect on the quantities of interest, but marginally increased reflection at the outlet.

The hull geometry used for simulation was taken from the digital 3D geometry created during the design of the segmented model [1, 14]. Under test conditions, the HSM was fitted with latex seals at the hull segment joints, a lightweight spray shield was fitted to the bow and the inside of the model was open to the air exposing the internal carbon fibre surfaces, aluminium framing and instrumentation. In the simulation, the geometry was capped with a flat top and the geometry at the latex seals was modelled as the design 
geometry such that the hull sides and underside were smooth and continuous. The spray shield and towing tank carriage geometry were omitted from the simulation geometry.

A moving reference frame was used to model the hull forward motion. The hull was free to heave (vertical translation) and pitch (rotation about the horizontal transverse axis) and constrained in all other degrees of freedom. While slamming leads to variation in forward speed, the associated surge motion was constrained to replicate the experimental configuration. First order Stokes waves were used to specify the time varying boundary condition on the velocity inlets and the pressure outlet. Boundary damping was applied on the downstream outlet and the grid was coarsened toward the outlet to minimise reflections. Turbulence was modelled using the Menter Shear Stress Transport (SST) model [48]. The turbulent boundary layer was modelled using wall functions with the grid spacing at the wall sized to ensure that the dimensionless wall distance remained within the range $30<y^{+}<300$. Surface tension and air compressibility were neglected on the basis that Swidan [31] achieved good correlation under the same assumption in 3D drop tests of a generic wave-piercing catamaran bow at more severe impact speeds (up to $4 \mathrm{~ms}^{-1}$ at model-scale) than were being considered in the regular head sea simulations (up to $1.1 \mathrm{~ms}^{-1}$ observed experimentally [1] in $90 \mathrm{~mm}$ waves at a forward speed of $2.89 \mathrm{~ms}^{-1}$ at model-scale).

To ensure proper modelling of the free surface it is critical that the mesh in the vicinity of the free surface is fine enough to resolve the free surface features. The ITTC practical guidelines for Ship CFD Applications [47] recommend that for regular waves there are at least 20 cells per wave height and at least 80 cells per wave length. For the large wavelength and small wave heights which are of interest for high speed catamarans, the number of cells per wave height becomes the limiting factor if a reasonable cell aspect ratio is to be maintained. This leads to relatively high cell counts even with coarse grids. Anisotropic refinement of the mesh near the free surface was used and the effect of number of cells per wave was investigated in the grid dependence study (Section 6).

Local refinements were made by either specifying mesh sizing on specific boundaries or by a defined volume region. An overview of the mesh and relevant refinement zones is shown in Figure 8. The mesh shown is the fine mesh from the grid dependence study. The primary free surface refinement encapsulates the region in which the free surface is expected to occur. Two additional refinement zones below the free surface were included with the 
typical cell dimensions increasing by a factor of 2 in each zone. These zones were introduced to manually control the mesh growth rate in the grid refinement study. The Kelvin wedge refinement zone was also included to control aspect ratio in the wake region - no attempt was made to meet the ITTC recommendation of 20 cells per wave height and 80 per wave length for the wake as such a mesh would result in cell counts which were not manageable given the available computational resource. Mesh coarsening over the free surface zone toward the outlet was implemented in two stages with the typical cell dimension in each region doubling relative to the upstream region.

An overset mesh was used for both the one-way and two-way interaction simulations to allow for the motion of the hull relative to the background domain. For the two-way interaction simulations, mesh morphing was additionally applied to the overset region to capture the deformation of the hull. The large rigid body motions resulted in overall translation and rotation of the overset domain while the structural deformations resulted in superimposed deformation the overset fluid domain mesh.

An expanded view of the near hull region is shown in Figure 9. The boundary of the overset region (parallel and perpendicular to the hull topside) can be seen due to the bow down pitch angle of the hull. The hull motions were such that the forward demihull sections and lower portion of the centre bow could move below the primary free surface refinement. For simulations using a fine mesh, it was found that the primary free surface refinement zone needed to be extended further below the free surface for the region upstream of the hull to reduce interpolation errors between the two numerical regions defined by the background and overset meshes. This additional refinement zone was included for the grid dependence study. Wedge shaped refinement zones were used in the overset region to minimise the cell count while still ensuring that the free surface was resolved well when the overset region was translated and rotated with hull motion. An isometric view of the mesh is provided in Figure 10 during bow entry with the free surface shown and a transverse cross-section view with hull surface mesh overlaid is shown in Figure 11.

Figure 12 shows the pressure distribution and cross sections of the flow field during centre bow water entry and arch slam. The jet flows formed by water entry of the demihull and centre bow are visible and a highly localised high pressure region can be seen to form as the two jet flows meet at the top of the arch way marking the onset of the arch slam. The volume fraction plots on the right hand side columns of the figure show that the free surface 
interface remains sharp throughout bow entry and the pressure distribution images in the left hand side column illustrate that the selected mesh was sufficiently fine to capture the pressure gradients. The black outline on the pressure distribution images depicts the boundary of the free surface and thus indicates which areas of the hull are wetted.

By modelling the HSM segments as rigid, the number of flexural modes was limited and so too was the highest structural modal frequency allowing the time step size used to be larger than it would otherwise have needed to be. The ITTC Practical Guidelines for Ship CFD Applications recommends at least 100 time steps per period for general periodic phenomena. The wet modal frequency of the second longitudinal bending mode was found to be $30.9 \mathrm{~Hz}$ (or a period of $0.032 \mathrm{~s}$ ) and on this basis the maximum allowable time step would be $0.32 \mathrm{~ms}$. A time step size of $0.25 \mathrm{~ms}$ was used. 


\section{Structural Domain}

In the structural domain, the $2.5 \mathrm{~m}$ long HSM developed by Lavroff [1] was represented. It is shown schematically in Figure 13. While a finite element model would typically be relied upon for full-scale analysis, the physical HSM was available, so the system parameters were identified using experimental methods. For completeness the main features of the model are described here. The model has three longitudinal segments connected by aluminium links centred at $830 \mathrm{~mm}$ and $1410 \mathrm{~mm}$ forward of the transom. The aft wetdeck is cantilevered from the mid segment and the aft port and starboard segments are separately and independently mounted to the mid segment. The forward port and starboard segments are also independently mounted to the mid segment and are connected by an elastically mounted centre bow segment via two transverse beams. The connections to the forward demihull segments are via pin joints preventing transmission of any moment about the longitudinal axis of the hull. At a scale of 1:44.8, the segmented model was designed to have dynamic similitude with a full scale $112 \mathrm{~m}$ vessel in the first longitudinal bending mode by selecting an appropriate link stiffness for the aluminium elastic links in the demihulls [9]. The elastic links in the transverse beam structure which mounts the centre bow segment to the demihulls were designed with appropriate stiffness to measure the centre bow loads with sufficient sensitivity. As a result, the vibration modes associated with strong relative motion between the centre bow and demihull segments have frequencies approximately four times larger than the fundamental longitudinal bending mode. In the structural model, it was assumed that the model response was symmetrical about the vertical longitudinal plane (as only head seas were considered here). It was additionally assumed that the centre bow and forward demihull segments could be modelled rigidly as the deformation in this region would lead to unfavourable shearing of the fluid domain mesh at the intersections between the centre bow and forward demihull segments.

For two-way interactions, a model with the dry structural system parameters is needed as all fluid effects are allowed for through the two-way interaction approach. The system mode shapes and frequencies in air were identified by suspending the model from soft springs and measuring the impulse response to impacts applied by an impulse hammer. The hull response was measured using roving accelerometers mounted to the port and starboard aluminium frame in the demihulls and on the centre bow transverse beams. The suspension spring stiffness resulted in rigid body oscillation frequencies 
Table 1: Modal frequencies and damping ratios of the segmented model longitudinal bending modes in air.

\begin{tabular}{|c|c|c|}
\hline Mode number & Modal Frequency (Hz) & Damping Ratio \\
\hline 1 & 17.1 & 0.0072 \\
\hline 2 & 34.5 & 0.0125 \\
\hline
\end{tabular}

less than $1 / 5$ th of the fundamental longitudinal bending mode frequency as was done by Dessi [49]. Accelerations were measured at three longitudinal locations on each demihull frame section to identify any deformation of the aluminium frame. No such deformation was observed in the two longitudinal bending mode shapes and this allowed the segments to be modelled as rigid with all flexibility isolated in the demihull elastic links. The impulse responses were used to estimate the orthonormal mode shapes and generate modal mass and stiffness matrices from which the mass and stiffness matrices were estimated using the modal transform definition. Damping ratios were estimated from the response decay rates [50]. The resulting system was then verified by first computing the impulse response to a measured impulse hammer transient from an independent hammer test and then comparing the predicted response to the experimentally measured response. The resulting dry system mode shapes in air are presented in Figure 14 and the undamped frequencies and damping ratios of the two longitudinal bending modes in air are shown in Table 1 . The structural domain mesh is also visible in these mode shapes. While the segments are considered rigid, the hull geometry and an appropriate mesh is required to map the fluid domain forces to the structural domain. In regions where the fluid pressure will not vary significantly (such as above the waterline on the aft segment) it was not necessary to refine the mesh to the same level as other regions where significant gradients exist in the fluid domain (for example the centre bow segment).

Having elected to model the HSM using lumped rigid masses as explained above, the computational penalty associated with a two-way interaction approach is reduced relative to using a full FE model of the hull. However, the time penalty for the two-way interaction approach is still significant as the fluid domain forces must still be mapped to the structural domain, the structural deformations mapped to the fluid domain and the fluid domain mesh deformed for every iteration of every time step in the overall solution. Thus, even with this simpler structural model, an effective and sufficiently accurate one-way interaction approach is still sought to reduce transient slamming 
Table 2: Modal frequencies and damping ratios of the segmented model longitudinal bending modes in water.

\begin{tabular}{|c|c|c|}
\hline Mode number & Modal Frequency (Hz) & Damping Ratio \\
\hline 1 & 13.8 & 0.01 \\
\hline 2 & 30.9 & 0.014 \\
\hline
\end{tabular}

simulation times.

For one-way interaction simulation, the added water terms must be allowed for in the structural domain as the vibratory response of the hull is not present in the fluid domain. Impulse hammer tests were conducted in still water at zero speed to provide a reference estimate of these terms. While of little use for the forward segment due to the large variations in immersion, the variation in immersed depth of the mid and aft segments is significantly less allowing the terms from the still water zero speed tests to be used as an approximation. The impulse hammer was again used with roving accelerometers and the system parameters were again used to estimate the mass matrix, stiffness matrix and damping ratios. The mode shapes were similar to those in air with node locations changing slightly. The undamped frequencies and damping ratios of the two longitudinal bending modes in still water at zero speed are shown in Table 2. The treatment of the added water terms in one-way interaction simulation are as discussed in Section 2. 


\section{Verification}

Verification was conducted for the rigid hull simulations considering the time step size $\Delta t$, minimum grid size $\Delta z$ and number of iterations per time step $n_{i i}$. The effects of turbulence modelling were assessed by running laminar and inviscid simulations. No significant difference in motions or loads was observed suggesting that the solution is not sensitive to the choice of turbulence model. For the time step dependence study, six time step sizes were considered with a refinement ratio of 2 . The following time steps were considered: $2 \times 10^{-3} \mathrm{~s}, 1 \times 10^{-3} \mathrm{~s}, 5 \times 10^{-4} \mathrm{~s}, 2.5 \times 10^{-4} \mathrm{~s}, 1.25 \times 10^{-4} \mathrm{~s}$ and $6.25 \times 10^{-5} \mathrm{~s}$ (between 325 and 10,400 time steps per wave encounter). A coarse mesh was used to provide reasonable solver times with the cell height in the free surface zone being $7.2 \mathrm{~mm}$ resulting in 12.5 cells per wave height and a total cell count of $433 \mathrm{k}$ cells. While this is coarser than generally recommended by the ITTC guidelines [47] it was found that there was minimal decay in wave amplitude through the domain and that reasonable estimates of the motions and loads could be obtained using such a grid when considering grid dependence. This is most likely due to the high forward speed of the vessel transporting the wave through the domain quickly. In turn, there are relatively few wave cycles as the wave passes through the domain, significantly reducing any decay of wave amplitude as it transits the domain.

The grid convergence study considered four meshes with a refinement ratio of $\sqrt{2}$ and minimum vertical cell sizes over the free surface of $12.73 \mathrm{~mm}$, $9 \mathrm{~mm}, 6.364 \mathrm{~mm}$ and $4.5 \mathrm{~mm}$ resulting in 7, 10, 14 and 20 cells per wave height respectively and cell counts of $5.41 \times 10^{5}, 1.25 \times 10^{6}, 3.17 \times 10^{6}$ and $8.17 \times 10^{6}$ respectively. Again, the high ship length Froude number results in the excitation waves having long wavelengths relative to their height, increasing the total cell count if cell aspect ratios are to be controlled. For grid convergence, the cell size in the horizontal plane was set to give an aspect ratio of 4 resulting in horizontal cell sizes of $50.9 \mathrm{~mm}, 36 \mathrm{~mm}, 25.5 \mathrm{~mm}$ and $18 \mathrm{~mm}$ corresponding to 64, 91, 129 and 183 cells per wave length which meets the recommendation [47] of 80 cells per wave length for all but the coarsest mesh.

Convergence with respect to the number of iterations per time step was assessed using 5, 7, 10, 14 and 20 iterations per time step, giving an average refinement ratio of $\sqrt{2}$.

Amplitudes of the time varying heave and pitch motion were used for the grid convergence study along with the peak vertical slam force acting on the 
centre bow segment of the model. The local maxima (and minima for motion records) were extracted over each simulated wave encounter and averaged for each record. The standard deviation of the data sets was also calculated and is demonstrated graphically in the plots using error bars. The time varying heave, pitch and centre bow force records are shown in Figure 15 for reference. The phase offset between the heave, pitch and centre bow force records show that for this wave condition, the arch slam event (which can be identified by the sharp spike in centre bow force) occurs when the hull is pitched bow down with some downward heave displacement. This is relatively typical for the slam events on wave-piercing catamarans in regular seas. A detailed analysis of the wave-piercing catamaran slamming kinematics over a range of conditions is given by Lavroff et al. [18].

The variation in motion and force amplitudes over the grid convergence criteria are shown in Figure 16 graphically and tabulated in Tables 3 through 5. The tabulated data includes the average dimensionless heave, pitch and force amplitudes as well as the convergence ratios $R_{\tau}, R_{G}$ and $R_{I}$ (for time step, grid and inner iterations respectively) between each refinement and for each considered variable. Negative convergence ratios are observed for all considered parameters indicating oscillatory convergence. For this reason, the largest practical range of convergence parameters was considered ensuring that more than three refinement levels were considered for each parameter. Changes in the solution are less than the variation within the solution for $\Delta t \leq 0.0005 \mathrm{~s} \Delta z \leq 6.364 \mathrm{~mm}$ and $n_{i i} \geq 5$. The one-way interaction simulations were therefore run using a time step of $\Delta t=0.0005 \mathrm{~s}$ $\Delta z=7.2 \mathrm{~mm}$ and a variable number of inner iterations with $5 \leq n_{i i} \leq 20$. The variable inner iterations were controlled by asymptotic criteria on the motion and force values between time steps.

As recommended by Stern et al. [51] the simulation numerical uncertainty was estimated from the maxima and minima of the oscillations in the convergence study data. The uncertainties are presented in Tables 6 through 8. Uncertainty due to grid spacing is the most significant contributor. The uncertainty might be improved by considering finer meshes. However, this was not possible with the available computing resource and is left for future work. 
Table 3: $R_{\tau}$, convergence ratio of solution with respect to time step size for: heave and pitch response amplitudes; and average peak centre bow force.

\begin{tabular}{|c|c|c|c|c|c|c|c|}
\hline Solution & \multirow{2}{*}{$\begin{array}{c}\Delta t \\
\text { Index }\end{array}$} & \multicolumn{2}{|c|}{ Heave } & \multicolumn{2}{c|}{ Pitch } & \multicolumn{2}{c|}{ Force } \\
\cline { 3 - 8 } & {$[\mathrm{ms}]$} & Amp. ${ }^{\dagger}$ & $R_{\tau}$ & Amp. ${ }^{\dagger}$ & $R_{\tau}$ & Amp. $^{\ddagger}$ & $R_{\tau}$ \\
\hline 1 & 0.0625 & 0.652 & & 0.682 & & 3.76 & \\
\hline 2 & 0.125 & 0.649 & 0.362 & 0.683 & -0.274 & 3.71 & 0.344 \\
\hline 3 & 0.25 & 0.639 & -1.29 & 0.680 & -0.529 & 3.56 & -0.591 \\
\hline 4 & 0.5 & 0.647 & -5.98 & 0.685 & 0.602 & 3.81 & -0.789 \\
\hline 5 & 1 & 0.646 & -0.171 & 0.693 & 0.298 & 3.50 & 0.392 \\
\hline 6 & 2 & 0.653 & & 0.721 & & 2.71 & \\
\hline $\begin{array}{l}\dagger \\
\dagger\end{array}$ \\
$\ddagger$
\end{tabular}

Table 4: $R_{G}$, convergence ratio of solution with respect to grid spacing for: heave and pitch response amplitudes; and average peak centre bow force.

\begin{tabular}{|c|c|c|c|c|c|c|c|}
\hline Solution & $\Delta z$ & \multicolumn{2}{|c|}{ Heave } & \multicolumn{2}{c|}{ Pitch } & \multicolumn{2}{c|}{ Force } \\
\cline { 3 - 8 } Index & {$[\mathrm{mm}]$} & Amp. ${ }^{\dagger}$ & $R_{G}$ & Amp. $^{\dagger}$ & $R_{G}$ & Amp. $^{\ddagger}$ & $R_{G}$ \\
\hline 1 & 4.5 & 0.657 & & 0.689 & & 3.95 & \\
\hline 2 & 6.364 & 0.670 & -0.693 & 0.705 & -0.486 & 4.26 & -0.484 \\
\hline 3 & 9 & 0.651 & 0.410 & 0.672 & -1.67 & 3.62 & -0.932 \\
\hline 4 & 12.73 & 0.603 & & 0.692 & & 4.30 & \\
\hline $\begin{array}{l}\dagger \\
\ddagger\end{array}$ Dimensionless response amplitude \\
$\ddagger$ Dimensionless average peak centre bow force \\
\hline
\end{tabular}

Table 5: $R_{I}$, convergence ratio of solution with respect to number of inner iterations $n_{i i}$ for: heave and pitch response amplitudes; and average peak centre bow force.

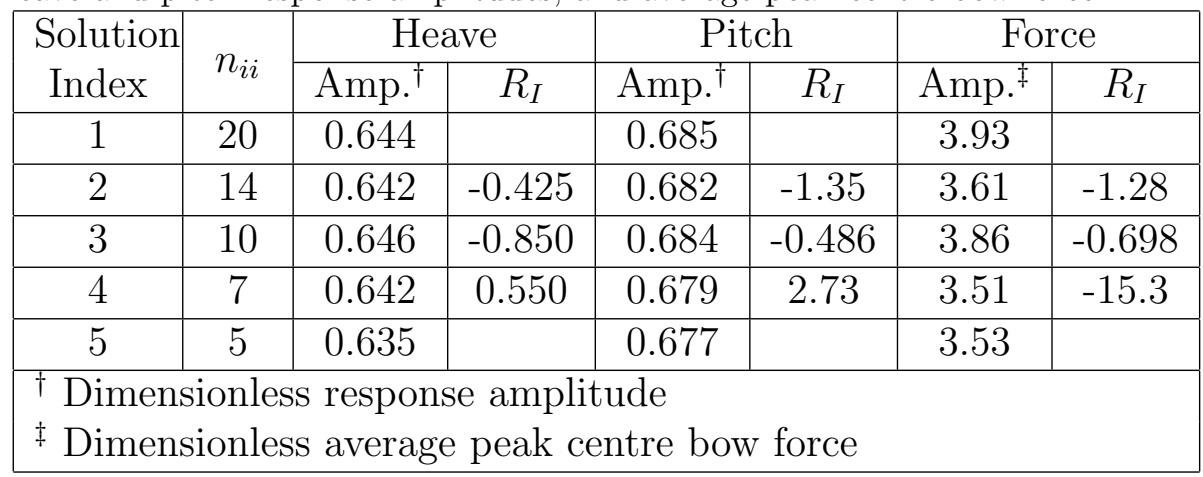


Table 6: Uncertainty and variability due to time step size $\left(U_{\tau}\right.$ and $\left.\sigma_{\tau}\right)$ as a percentage of the mean motion (heave and pitch) and centre bow force for a forward speed of $2.89 \mathrm{~m} / \mathrm{s}$, wave height of $90 \mathrm{~mm}$ and dimensionless wave encounter frequency of $\omega_{e}^{*}=4.869$.

\begin{tabular}{|c|c|c|}
\cline { 2 - 3 } \multicolumn{1}{c|}{} & Uncertainty $U_{\tau}$ & Standard Deviation $\sigma_{\tau}$ \\
\hline Heave & $1.0 \%$ & $9.0 \%$ \\
\hline Pitch & $1.0 \%$ & $6.1 \%$ \\
\hline Centre Bow Force & $4.2 \%$ & $13.0 \%$ \\
\hline
\end{tabular}

Table 7: Uncertainty and variability due to grid spacing $\left(U_{G}\right.$ and $\left.\sigma_{G}\right)$ as a percentage of the mean motion (heave and pitch) and centre bow force for a forward speed of $2.89 \mathrm{~m} / \mathrm{s}$, wave height of $90 \mathrm{~mm}$ and dimensionless wave encounter frequency of $\omega_{e}^{*}=4.869$.

\begin{tabular}{|c|c|c|}
\cline { 2 - 3 } \multicolumn{1}{c|}{} & Uncertainty $U_{G}$ & Standard Deviation $\sigma_{G}$ \\
\hline Heave & $5.2 \%$ & $5.1 \%$ \\
\hline Pitch & $2.3 \%$ & $3.1 \%$ \\
\hline Centre Bow Force & $8.5 \%$ & $14.3 \%$ \\
\hline
\end{tabular}

Table 8: Uncertainty and variability due to number of iterations per time step $\left(U_{I}\right.$ and $\left.\sigma_{I}\right)$ as a percentage of the mean motion (heave and pitch) and centre bow force for a forward speed of $2.89 \mathrm{~m} / \mathrm{s}$, wave height of $90 \mathrm{~mm}$ and dimensionless wave encounter frequency of $\omega_{e}^{*}=4.869$.

\begin{tabular}{|c|c|c|}
\cline { 2 - 3 } \multicolumn{1}{c|}{} & Uncertainty $U_{I}$ & Standard Deviation $\sigma_{I}$ \\
\hline Heave & $0.9 \%$ & $3.0 \%$ \\
\hline Pitch & $0.6 \%$ & $2.6 \%$ \\
\hline Centre Bow Force & $6.1 \%$ & $19.5 \%$ \\
\hline
\end{tabular}


Table 9: Validation Uncertainty $\left(U_{V}\right)$ for Heave, Pitch and Centre Bow Force

\begin{tabular}{|c|c|}
\hline Heave & $7.4 \%$ \\
\hline Pitch & $5.6 \%$ \\
\hline Centre Bow Force & $15.1 \%$ \\
\hline
\end{tabular}

\section{Validation and Results}

For validation, the comparison error $E$ must be less than the validation uncertainty $U_{V}^{2}=U_{D}^{2}+U_{S N}^{2}$, where $U_{D}$ is the experimental uncertainty and $U_{S N}$ is the simulation uncertainty. A lower bound on the experimental uncertainty was estimated to be $\pm 5 \%$ [52] for the heave and pitch responses and $\pm 10 \%$ for the slam force and hull bending moments as these correlate to wave height squared [1]. The simulation numerical uncertainty is the rootsum-of-squares of the contributions from factors considered in the simulation verification. In this case, the contributions from time step $U_{\tau}$, grid size $U_{G}$ and number of inner iterations $U_{I}$ are considered giving: $U_{S N}^{2}=U_{\tau}^{2}+U_{G}^{2}+U_{I}^{2}$. The resulting validation uncertainties are presented in Table 9.

Motion records for rigid and hydroelastic simulations compared with experimental results are shown in Figure 17 for a nominal wave height of $90 \mathrm{~mm}$, at a forward speed of $2.89 \mathrm{~m} / \mathrm{s}$ and a dimensionless wave encounter frequency of $\omega_{e}^{*}=4.869$, (corresponding to the experimentally observed wave encounter frequency of greatest slam force for the given wave height and forward speed). The experimental wave elevation is based on an extrapolated record from a resistive moving wave probe in line with the vessel's Longitudinal Centre of Gravity (LCG). The resistive wave probe readings were affected by forward speed resulting in poor measurement of the surface elevation near the hull. For this reason, the experimental wave amplitudes from static wave probes were used to convert data to non-dimensional form and the moving wave probes used as a reference for the phase relationship between the motion and wave excitation.

The simulated responses are generally of smaller amplitude than the experimental response with increased variation between wave encounters. The transient form of the records agree particularly well as does the relative phase relationship between the heave and pitch records which is identified by the small time difference between corresponding peaks, troughs and zerocrossings. There is a noticeable change in mean heave (or sinkage in waves) between the rigid (one-way interaction) and hydroelastic (two-way interac- 
tion) simulations, with the hydroelastic simulation generally being closer to experiment. Deformation of the hull is greatest during bow entry and this generates hull sagging. However, the sagging deformations during bow entry are small, being approximately $2 \mathrm{~mm}$ deviation at the mid ship section from a line between the forward and aft perpendiculars. This level of deformation (approximately $0.1 \%$ of $L_{p p}$ ) would not be sufficient to alter the mean heave (i.e. sinkage) significantly. The hydroelastic simulation also exhibits harmonic distortion resulting from hull bending, most noticeable in the heave record near the local minima. This is a result of the changing water-plane area with varying bow immersion introducing non-linearities which are most significant when the arch between the centre bow and demihulls fills resulting in the slam impact.

While the simulated and experimental transient centre bow forces also shown in Figure 17 have similar characteristics, they measure different physical quantities. The experimental result represents a measurement of the summation of the hydrodynamic forcing term and the centre bow segment inertial force. Lavroff estimated that the inertial force magnitude is up to $17 \%$ [16] of the measured total force. In both one-way and two-way interaction simulations, the centre bow force was computed by directly integrating the pressure distribution resulting from the unsteady RANS equation solution over a geometry patch which matched the surface of the isolated centre bow segment of the HSM. In the one-way interaction simulation, the force record represents the transient hydrodynamic force acting on the centre bow segment, and for the two-way interaction simulation it represents the same only including hydrodynamic terms which arise due to the hull whipping response. Thus, the centre bow force is not a suitable choice of variable for validation. For this reason, the hull bending response was chosen for quantitative validation analysis along with the heave and pitch motion responses.

The dimensionless heave and pitch as functions of the wave encounter frequency are presented in Figures 18 and 19. As the experimental dataset is more densely populated, a dashed line has been used to connect these data points rather than the more sparse simulation data. The comparison error is shown in both figures along with lines indicating the validation uncertainty $\pm U_{V}$. Qualitatively, the motion is well predicted by both simulations over the range of encounter frequencies considered, which include those associated with peak pitch motion, peak heave motion and peak slam force $\left(\omega_{e}^{*}=3.216,3.644\right.$ and 4.869 respectively). Although the data is rather sparse in the vicinity of the peak heave and pitch wave encounter frequencies, 
the simulated and experimental results exhibit peak motion at the same wave encounter frequencies. The high frequency tail of the Response Amplitude Operator $(\mathrm{RAO})$ is also well predicted $\left(\omega_{e}^{*}>4\right)$ though the comparison error as a percentage becomes large due to the small overall motion amplitudes in the tail. For intermediate wave encounter frequencies $3.5<\omega_{e}^{*}<5.5$ (with the exception of the rigid simulations at $\omega_{e}^{*}=4.587$ and $\left.\omega_{e}^{*}=4.869\right)$ the validation uncertainty for heave is greater than the heave comparison error and validation is achieved at $U_{V}=7.4 \%$. For higher frequencies, validation of the simulated heave amplitudes is not formally achieved though the absolute comparison error is small (owing to the small heave motion amplitudes). A large comparison error is also observed for both rigid and hydroelastic simulations at a wave encounter frequency of $\omega_{e}^{*}=3.216$, corresponding with the frequency at which peak pitch motion is observed. The experimental RAO exhibits a sharp reduction at this particular encounter frequency which is not replicated in the simulated results. Validation of the pitch motion was achieved at $U_{V}=5.6 \%$ over a wider range of encounter frequencies. Only the encounter frequency corresponding to peak heave motion fell outside the comparison error.

Figure 20 shows the experimental transient bending moment at the forward and aft segment links of HSM01 compared to the simulated values as predicted using two-way interaction simulation, one-way interaction simulation with variable added mass on the bow segment and one-way interaction with constant added mass. First considering the comparison between the two-way interaction and experimental result it is clear that the peak sagging bending moment (positive) is under-estimated in simulation at both the forward and aft segment links, while the peak hogging bending moment (negative) is over predicted by simulation for the forward link. Some higher frequency content evident in the experimental records, most noticeable at the first sagging and hogging peaks, is not replicated in the simulated data which considers the three forward hull segments as rigidly connected. This higher frequency content contributes somewhat to increase the peak Vertical Bending Moment (VBM) in the experimental results and cannot be replicated in simulation without including the additional system degrees of freedom.

The total bending moment range (peak sagging minus peak hogging moment) is similar for experiment and simulation. However, an offset is not sufficient to explain the difference between simulation and experiment as the mean bending moment between slam events is similar. Both the experimental and simulated VBM records show decaying oscillation dominated by the 
fundamental bending mode which reaches a minimum prior to bow entry, approximately three quarters of a wave encounter period after the previous slam event. The oscillation amplitude is then seen to increase prior to the next arch slam. This is presumably due to bottom slamming and entry of the demihull segments which is the initial phase of water entry. For the VBM at the forward link, the decay is somewhat more rapid reaching a minimum amplitude approximately half an encounter period after the slam and is followed by an increase in amplitude over the second half of the wave encounter period. Additionally, in the experimental data there is very little oscillation in the increase in VBM immediately prior to the slam. This is somewhat replicated in the two-way interaction simulation - with only a small reversal in bending during the loading phase. The wet whipping frequency is quite well predicted by the two-way interaction simulation which requires that the time variation of added mass be well represented. The simulated VBM during the slam event has a significantly shorter characteristic duration when compared with experiment - though the rebound time between peak sagging and peak hogging bending moment is similar. The overall qualitative match between two-way interaction simulation and experiment is reasonable, though there are clear quantitative discrepancies.

Considering the one-way interaction simulation results it can be seen that the magnitudes of the VBM throughout the wave encounter period are similar in magnitude to those predicted by two-way interaction. The most notable difference is the large peak bending moment in the aft link when added mass is treated as constant and the increase in whipping frequency for the constant added mass simulation. For design, it is the peak bending moment distribution, whipping response magnitude and number of cycles which are of importance and all three are well predicted by one-way interaction simulation with time varying added mass distribution. The solution with time-varying added mass has a reduced modal period while the bow is immersed, but the reduction is not as large as that predicted by two-way interaction simulation or indeed the experimental result. Thus, all simulation methods appear to under-predict the water added mass term.

In the case of two-way interaction simulation, the added mass appears to be only fractionally under-predicted with the local peaks and troughs in the girder vibration response being nearly coincident with the experimental results. For the one-way interaction simulation with time varying added mass, the under-prediction in added mass can mainly be attributed to use of the undisturbed water surface when determining the water added mass. 
As the effective deadrise angle of the hull surface near the top of the arch is very small, local water up-rise could lead to significant changes in the water added mass, particularly in relation to arch filling. That is, using the undisturbed free surface may result in arch filling not being accounted for in the added mass calculation during the one-way interaction simulations. For the one-way interaction with constant added mass, the added mass is clearly under-predicted as would be expected when using the still-water added mass. As a result, the combined structural and added mass matrix is imbalanced resulting in incorrect bending moment magnitudes. Thus, while the bending moment magnitudes predicted are numerically closer to the experimental values, this is nothing more than coincidental.

The maximum sagging bending moment produced by the slam event was taken as the metric for validation. There were two reasons for this choice. Firstly, the peak slamming force and resulting peak bending moment can be expected to have some form of correlation and secondly, in order to use the simulations for design, confidence in predicting extreme cases is necessary. The peak sagging bending moment is shown for the various solution approaches in Figures 21 and 22. In all simulations, the peak bending moment at the forward link is generally under-predicted while, for the aft link, the peak bending moment is predicted reasonably well by all simulations with the exception of the one-way interaction simulation with constant added bow mass which significantly over-predicts the aft bending moment. The comparison errors for the forward and aft VBMs are also shown. From the comparison error, it is clear that the simulation cannot be validated for VBM at the uncertainty level $U_{V}=15.1 \%$.

To objectively consider the performance of the with one-way interaction simulation with varying added mass relative to those with two-way interaction the solutions of these two approaches are compared directly without consideration of other results. Figure 23 shows the predicted transient bending records at the forward link. It can be seen that the magnitude of the hull girder vibration predicted by one-way interaction simulation with time varying added mass is very similar to that of two-way interaction simulation. This is also true of the peak hogging and sagging bending moments on each wave encounter. The magnitude of the aft bending moment predicted by the one-way interaction method was typically found to be larger than that predicted by the two-way interaction approach similarly resulting in a conservative design load case. The correlation between the one-way and two-way interaction simulations was quite consistent across the range of en- 
counter frequencies considered as is evident in Figures 21 and 22. Thus, the one-way interaction approach proposed is suitable for design where available computing resource is limited or where more rapid solutions are desired.

\section{Conclusion}

A new one-way interaction simulation approach suitable for wave-piercing catamarans has been proposed, implemented and tested with verification and validation against model-scale experimental results. The proposed one-way interaction method uses a new hemispherical added mass model and accounts for time variation in added mass which is significant for wave-piercing catamarans. The approach allows for reduced solver times by allowing larger time step sizes than are required for two-way interaction simulation to capture the hull girder response frequencies which are typically an order of magnitude larger than wave encounter frequencies in the case of a wave-piercing catamaran. In addition, one-way interaction eliminates the need to deform the fluid domain mesh and exchange the fluid loading and structural response displacements at each iteration of each time step providing further reductions in the computational effort.

Formal convergence studies on the number of inner iterations, grid spacing and time step size have been conducted. The simulation numerical uncertainty was quantified as 5.4\%, 2.6\% and $11.3 \%$ for the heave, pitch and centre bow force magnitudes respectively. Oscillatory convergence was observed requiring that time step and grid convergence studies be conducted for more than 3 refinement levels. Due to the available computing resource, the convergence studies were limited to the rigid simulations only and the grid convergence study was limited to 4 levels with the finest level meeting the ITTC recommendations for the number of cells per wave height. In general it was found that solutions with free surface meshes coarser than recommended by the ITTC provided similar results with little decay in wave amplitude over the domain. This is likely due to the long wavelengths and high forward speeds causing the wave to transit through the moving domain quickly with reduced time for numerical diffusion relative to simulation of low Froude number vessels.

Validation of the heave and pitch motions was generally achieved at validation uncertainty levels of $U_{V}=7.4 \%$ and $U_{V}=5.6 \%$ respectively. The comparison error at some encounter frequencies fell outside this range, but were either in regions where the motion amplitudes were small or relating 
to the peak heave and pitch motion cases which are highly dependent on damping to limit the peak amplitude.

The validation effort for hull loading was less successful. The hull VBM was used as the variable in favour of the centre bow force as the centre bow force magnitude was dependent on the hull elasticity and analysis assumptions. For the VBM at the forward link the comparison error was generally larger than the validation uncertainty of $U_{V}=15.1 \%$. The comparison error for the VBM at the aft link was generally within the validation uncertainty range.

It is hypothesised that the under-prediction in VBM is associated with an increased duration of the bow entry phase leading to a reduction in relative velocity at the time of arch slam. In the absence of experimental data pertaining to the relative velocity in the archway which accounts for local water surface up-rise, it was not possible to compare simulated local relative velocities to experimental results to confirm this hypothesis. The under-prediction of the VBM represents a limitation of the current results. However, as the characteristics of the bending response are qualitatively very similar to the experimental work the current results still act to provide a realistic insight into the slamming characteristics of wave piercing catamarans. In design, there are also generally two capacities of analysis techniques: absolute and relative predictions. In the current state, the simulations could therefore be useful in the second capacity for comparative study between two designs. However, whilst prediction of short duration slamming loads is a very demanding task, further work could lead to somewhat increased accuracy of absolute predictions.

Hydroelastic coupling between the fluid and hull whipping response was found to be small with the choice of structural parameters having minimal influence on the slam force, but significant changes to the estimated hull bending. One-way interaction simulation was found to provide qualitatively and quantitatively similar results to two-way interaction simulations so long as the time variation in added mass is accounted for. For designers already using unsteady RANS equation based solvers in their design methodology, the addition of a one-way interaction solution adds little computational cost while giving the designer the ability to account for the global vibratory response when assessing the fatigue life as well as the affect of this dynamic response on the hull design loads. 


\section{Acknowledgements}

This work has been supported by INCAT Tasmania Pty Ltd, Revolution Design Pty Ltd, the Australian Research Council, the University of Tasmania and the Australian Maritime College. 
[1] J. Lavroff, The Slamming and Whipping Vibratory Response of a Hydroelastic Segmented Catamaran Model, Ph.D. thesis, University of Tasmania, 2009.

[2] R. Zhao, O. Faltinsen, J. Aarsnes, Water Entry of Arbitrary TwoDimensional Sections with and Without Flow Separation, in: TwentyFirst Symposium on Naval Hydrodynamics, National Academies Press, Washington, D.C., 1997, pp. 408-423.

[3] G. Thomas, M. Davis, D. Holloway, T. Roberts, The Whipping Vibration of Large High-Speed Catamarans, The International Journal of Maritime Engineering 145 (2003) 13-29.

[4] G. Thomas, M. Davis, D. Holloway, T. Roberts, The Vibratory Damping of Large High-Speed Catamarans, Marine Structures 21 (2008) 1-22.

[5] G. A. Thomas, M. R. Davis, D. S. Holloway, T. J. Roberts, Transient Dynamic Slam Response of Large High Speed Catamarans, in: FAST 2003, Ischia, Italy.

[6] G. A. Thomas, M. R. Davis, D. S. Holloway, T. Roberts, Extreme Asymmetric Slam Loads on Large High Speed Catamarans, in: Proceedings of the 6th Symposium on High Speed Marine Vehicles, Castello di Baia, Italy, pp. I.15-I.23.

[7] G. A. Thomas, M. R. Davis, D. S. Holloway, N. L. Watson, T. J. Roberts, Slamming Response of a Large High-Speed Wave-Piercer Catamaran, Marine Technology 40 (2003) 126-140.

[8] G. Jacobi, G. Thomas, M. R. Davis, G. Davidson, An Insight into the Slamming Behaviour of Large High-Speed Catamarans Through FullScale Measurements, Journal of Marine Science and Technology 19 (2014) 15-32.

[9] J. Lavroff, M. R. Davis, D. S. Holloway, G. Thomas, The Vibratory Response of High-Speed Catamarans to Slamming Investigated by Hydroelastic Segmented Model Experiments, International Journal of Maritime Engineering 151 (2009) 1-11.

[10] G. Thomas, M. Davis, D. Holloway, T. Roberts, S. Matsubara, J. Lavroff, W. Amin, K. Chamberlin, T. Dove, Characterisation of 
Slam Events of a High-Speed Catamaran in Irregular Waves, in: 10th International Conference on Fast Sea Transportation, FAST, Athens.

[11] J. Lavroff, M. R. Davis, D. S. Holloway, G. A. Thomas, Slamming of High-Speed Catamarans in Severe Sea Conditions Investigated by Hydroelastic Segmented Model Experiments, in: Proceedings of the 28th Symposium on Naval Hydrodynamics, California.

[12] G. Thomas, S. Winkler, M. Davis, D. Holloway, S. Matsubara, J. Lavroff, B. French, Slam Events of High-Speed Catamarans in Irregular Waves, Journal of Marine Science and Technology 16 (2010) 8-21.

[13] J. Lavroff, M. R. Davis, D. S. Holloway, G. Thomas, Determination of Wave Slamming Loads on High-Speed Catamarans by Hydroelastic Segmented Model Experiments, International Journal of Maritime Engineering 153 (2011) A185-A197.

[14] S. Matsubara, Ship Motions and Wave-Induced Loads on High Speed Catamarans, PhD Thesis, University of Tasmania, 2011.

[15] S. Matsubara, G. Thomas, M. Davis, D. Holloway, T. Roberts, Influence of Centrebow on Motions and Loads of High-Speed Catamarans, in: 11 th International Conference on Fast Sea Transportation, Honolulu.

[16] J. Lavroff, M. Davis, D. Holloway, G. Thomas, Wave Slamming Loads on Wave-Piercer Catamarans Operating at High-Speed Determined by Hydro-Elastic Segmented Model Experiments, Marine Structures 33 (2013) 120-142.

[17] J. R. Shahraki, The Influence of Hull Form on the Slamming Behaviour of Large High-Speed Catamarans, PhD Thesis, University of Tasmania, 2014.

[18] J. Lavroff, M. R. Davis, Slamming Kinematics, Impulse and Energy Transfer for Wave-Piercing Catamarans, Journal of Ship Research 59 (2015) 145-161.

[19] B. French, G. Thomas, M. Davis, Slam Characteristics of a High-Speed Wave Piercing Catamaran in Irregular Waves, Transactions of the Royal Institution of Naval Architects Part A: International Journal of Maritime Engineering 156 (2014) 25-36. 
[20] B. J. French, G. A. Thomas, M. R. Davis, Slam Occurrences and Loads of a High-Speed Wave Piercer Catamaran in Irregular Seas, Proceedings of the Institution of Mechanical Engineers, Part M: Journal of Engineering for the Maritime Environment 229 (2015) 45-57.

[21] B. French, Slamming of Large High-Speed Catamarans in Irregular Seas, PhD Thesis, University of Tasmania, 2012.

[22] J. R. Whelan, Wetdeck Slamming of High-Speed Catamarans with a Centre Bow, PhD Thesis, University of Tasmania, Australia, 2004.

[23] A. Swidan, G. Thomas, D. Ranmuthugala, W. Amin, I. Penesis, T. Allen, M. Battley, Experimental Drop Test Investigation into Wetdeck Slamming Loads on a Generic Catamaran Hullform, Ocean Engineering 117 (2016) 143-153.

[24] D. S. Holloway, A High Froude Number Time Domain Strip Theory Applied to the Seakeeping of Semi-SWATHs, PhD Thesis, University of Tasmania, Australia, 1998.

[25] D. S. Holloway, M. R. Davis, Ship Motion Computations Using a High Froude Number Time Domain Strip Theory, Journal of Ship Research 50 (2006) 15-30.

[26] M. Davis, D. Holloway, Passenger Motions on Equivalent Monohulls, Catamarans and Trimarans, in: 5th International Conference on High Performance Marine Vehicles, Australia.

[27] M. Davis, D. Holloway, Effect of Sea, Ride Controls, Hull Form and Spacing on Motion and Sickness Incidence for High Speed Catamarans, in: The 7th International Conference on Fast Sea Transportation, Naples.

[28] M. Davis, D. Holloway, The Influence of Hull Form on the Motions of High Speed Vessels in Head Seas, Ocean Engineering 30 (2003) 20912115 .

[29] M. R. Davis, J. R. Whelan, Computation of Wet Deck Bow Slam Loads for Catamaran Arched Cross Sections, Ocean Engineering 34 (2007) 2265-2276. 
[30] Q. Yang, W. Qiu, Numerical Simulation of Water Impact for 2d and 3d Bodies, Ocean Engineering 43 (2012) 82-89.

[31] A. Swidan, G. Thomas, D. Ranmuthugala, I. Penesis, W. Amin, T. Allen, M. Battley, Prediction of Slamming Loads on Catamaran Wetdeck using CFD, in: Proceedings of the 13th International Conference on Fast Sea Transportation, Washington DC.

[32] J. McVicar, J. Lavroff, M. R. Davis, G. Davidson, Transient Slam Load Estimation by RANSE Simulation and by Dynamic Modeling of a Hydroelastic Segmented Model, in: 30th Symposium on Naval Hydrodynamics, Hobart, Tasmania, Australia.

[33] J. McVicar, J. Lavroff, M. R. Davis, G. A. Thomas, Slam Excitation Scales for a Large Wave Piercing Catamaran and the Effect on Structural Response, in: Proceedings of the 13th International Conference on Fast Sea Transportation, Washington DC.

[34] C. Ge, O. M. Faltinsen, T. Moan, Global Hydroelastic Response of Catamarans Due to Wetdeck Slamming, Journal of Ship Research 49 (2005) 24-42.

[35] K. J. Paik, P. M. Carrica, D. Lee, K. Maki, Strongly Coupled FluidStructure Interaction Method for Structural Loads on Surface Ships, Ocean Engineering 36 (2009) 1346-1357.

[36] J. Oberhagemann, O. el Moctar, Numerical and Experimental Investigations of Whipping and Springing of Ship Structures, in: Proceedings of the Twenty-first International Offshore and Polar Engineering Conference, International Society of Offshore and Polar Engineers, Maui, Hawaii, USA, 2011.

[37] H. Rathje, A. Kahl, T. E. Schellin, High-Frequency Ship Response Assessment of Large Containerships, in: The proceedings of the twentyfirst International Offshore and Polar Engineering Conference, International Society of Offshore and Polar Engineers, Maui, Hawaii, USA, 2011, pp. 469-476.

[38] J. Yang, S. Kim, J. Park, B. Jung, T. Lee, Numerical analysis for slamming impact loads and dynamic structural responses of a containership, 
in: Proceedings of the 12th International Symposium on Practical Design of Ships and Other Floating Structures PRADS, Changwon, Korea.

[39] J. H. Kim, Y. Kim, R. H. Yuck, D. Y. Lee, Comparison of Slamming and Whipping Loads by Fully Coupled Hydroelastic Analysis and Experimental Measurement, Journal of Fluids and Structures 52 (2015) $145-165$.

[40] D. J. Piro, A Hydroelastic Method for the Analysis of Global Ship Response Due to Slamming Events, PhD Thesis, The University of Michigan, 2013.

[41] K. J. Maki, D. Lee, A. W. Troesch, N. Vlahopoulos, Hydroelastic Impact of a Wedge-Shaped Body, Ocean Engineering 38 (2011) 621-629.

[42] J. Ley, O. el Moctar, J. Oberhagemann, T. E. Schellin, Assessment of Loads and Structural Integrity of Ships in Extreme Seas, in: Proceedings of the 30th Symposium on Naval Hydrodynamics, Hobart, Tasmania, Australia.

[43] N. M. Newmark, A method of computation for structural dynamics, Journal of the Engineering Mechanics Division 85 (1959) 67-94.

[44] C. Förster, W. A. Wall, E. Ramm, The Artificial Added Mass Effect in Sequential Staggered Fluid-Structure Interaction Algorithms, in: Proceedings ECCOMAS CFD, TU Delft, Netherlands, 2006.

[45] Star-CCM+ v8.06.005 User guide, 2013.

[46] S. Muzaferija, M. Perić, Computation of Free-Surface Flows Using Interface-Tracking and Interface-Capturing Methods, in: O. Mahrenholtz, M. Markiewicz (Eds.), Nonlinear Water Wave Interaction, 1999, pp. 59-100.

[47] ITTC, ITTC - Recommended Procedures and Guidelines: Practical Guidelines for Ship CFD Applications, 2011.

[48] F. R. Menter, Two-Equation Eddy-Viscosity Turbulence Models for Engineering Applications, AIAA Journal 32 (1994) 1598-1605. 
[49] D. Dessi, R. Mariani, G. Coppotelli, Experimental Investigation of the Bending Vibrations of a Fast Vessel., Australian Journal of Mechanical Engineering 4 (2007) 125.

[50] W. Amin, Non-linear Unsteady Wave Loads on Large High-Speed Wave Piercing Catamarans, Ph.D. thesis, University of Tasmania, University of Tasmania, 2009.

[51] F. Stern, R. Wilson, J. Shao, Quantitative V\&V of CFD simulations and certification of CFD codes, International Journal for Numerical Methods in Fluids 50 (2006) 1335-1355.

[52] J. McVicar, Slam Induced Bending of High-Speed Wave-Piercing Catamarans, PhD Thesis, University of Tasmania, Tasmania, Australia, 2016. 


\section{List of Figures}

$185 \mathrm{~m}$ Incat wave-piercing catamaran "Akane". . . . . . . . . . 41

2 Geometric features of an Incat wave-piercing catamaran. . . . 42

3 Flow field shortly after arch slam event on the hydroelastic segmented model tested by Lavroff $[1] \ldots$. . . . . . . . . . . 43

4 Sectional added mass before and after arch closure as determined on a sectional basis. . . . . . . . . . . . . . . . . . 44

5 Illustrative example of using the horizontal plane radius to identify the radius to the nearest dry cell. For clarity, not all hemispherical fits are shown. In the implementation a radius is identified for every cell face. . . . . . . . . . . . . . . . 45

6 Calm water added mass distribution estimated using a hemispherical added mass distribution for a single demihull. The waterline is located at $z=0 \ldots \ldots \ldots \ldots$. . . . . 46

7 Domain boundary locations relative to the wave piercing catamaran hull for simulation of motions and slamming loads in head seas. . . . . . . . . . . . . . . . . . . 47

8 CFD domain mesh overview. The fine mesh from the grid dependence study is depicted. . . . . . . . . . . . . 48

9 Near hull CFD mesh. The fine mesh from the grid dependence study is depicted. . . . . . . . . . . . . . . . . . . . . . 49

10 Isometric view of the bow region including free surface. The fine mesh from the grid dependence study is depicted. . . . . . 50

11 Transverse cross-section view of mesh taken at frame $74(1.982 \mathrm{~m}$ from transom). The hull surface mesh overlaid on the crosssection view. The fine mesh from the grid dependence study is depicted. . . . . . . . . . . . . . . . . 51

12 Pressure distribution acting in the arch region at several time instances during centre bow entry. . . . . . . . . . . . . 52

13 Plan view schematic representation of the physical Hydroelastic Segmented Model showing the six individual segments. The links at the segment joints $1410 \mathrm{~mm}$ and $830 \mathrm{~mm}$ from the transom will be referred to as the forward and aft links respectively. . . . . . . . . . . . . . 
14 First (top) and second (bottom) bending modes of the finite element model in ABAQUS showing the generated structural domain surface mesh. (Note, the greatly exaggerated amplitudes of motion in the mode shape representation cause self intersecting geometry which does not occur in the transient simulations.) . . . . . . . . . . . . . . . . 54

15 Example time varying motion and force records estimated using one-way interaction simulation for a dimensionless wave encounter frequency of $\omega_{e}^{*}=4.869$, a forward speed of $2.89 \mathrm{~m} / \mathrm{s}$ and a wave height of $90 \mathrm{~mm} . . . . . . . . . . .555$

16 Convergence plots for solution dependence on grid, time step and number of iterations per time step. Error bars show plus and minus one standard deviation of the statistical variation between wave encounters in peak-to-peak amplitude. . . . . . 56

17 Dimensionless motion of rigid body simulation (left) and hydroelastic simulation (right) compared to experimental records for a dimensionless wave encounter frequency of $\omega_{e}^{*}=4.869$, a forward speed of $2.89 \mathrm{~m} / \mathrm{s}$ and a wave height of $90 \mathrm{~mm}$. The centre bow force has been included to allow the time of peak slam force to be identified in the records. . . . . . . . . . . 57

18 Simulated and experimental dimensionless heave response for a forward speed of $2.89 \mathrm{~m} / \mathrm{s}$ and a wave height of $90 \mathrm{~mm}$. . . . 58

19 Simulated and experimental dimensionless pitch response for a forward speed of $2.89 \mathrm{~m} / \mathrm{s}$ and a wave height of $90 \mathrm{~mm}$. . . . 59

20 Time domain bending response as measured experimentally compared to that predicted through: two-way interaction simulation, one-way interaction simulation with time varying added mass and one-way interaction simulation with constant added mass. The condition presented is for a dimensionless wave encounter frequency of $\omega_{e}^{*}=4.869$ at a forward speed of $2.89 \mathrm{~m} / \mathrm{s}$ and a wave height of $90 \mathrm{~mm}$. . . . . . . . . . . . . . . 60

21 Simulated and experimental dimensionless bending moment at the forward and aft segment joins for a forward speed of $2.89 \mathrm{~m} / \mathrm{s}$ and a wave height of $90 \mathrm{~mm}$. . . . . . . . . . . . . 61

22 Simulated and experimental dimensionless bending moment at the aft segment join for a forward speed of $2.89 \mathrm{~m} / \mathrm{s}$ and a wave height of $90 \mathrm{~mm}$. . . . . . . . . . . . . . . . 62 
23 Transient bending moment at the forward link as predicted by two-way interaction and one-way interaction with added mass. 63 


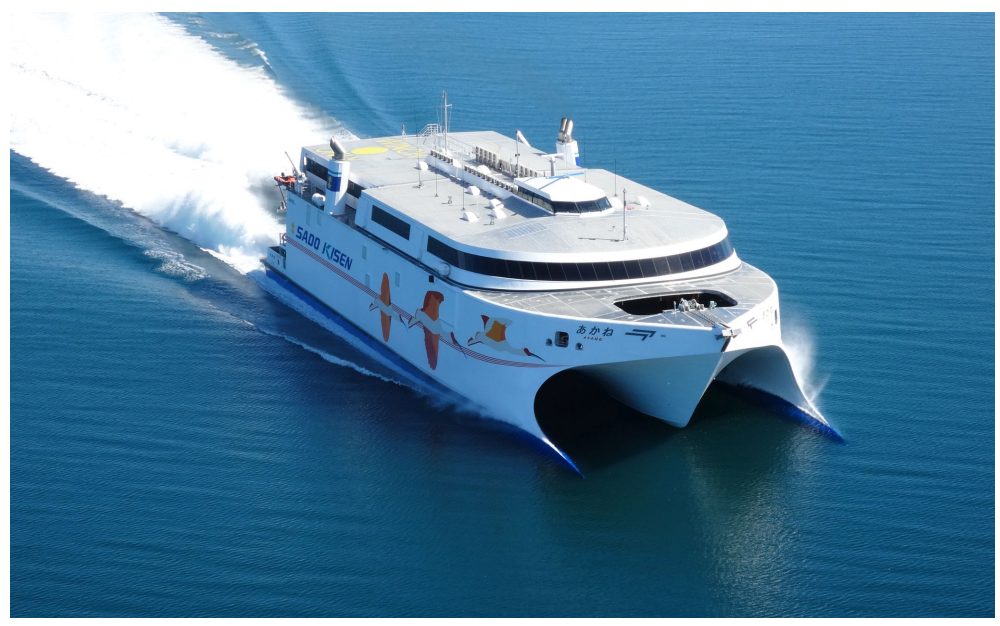

Figure 1: $85 \mathrm{~m}$ Incat wave-piercing catamaran "Akane". 


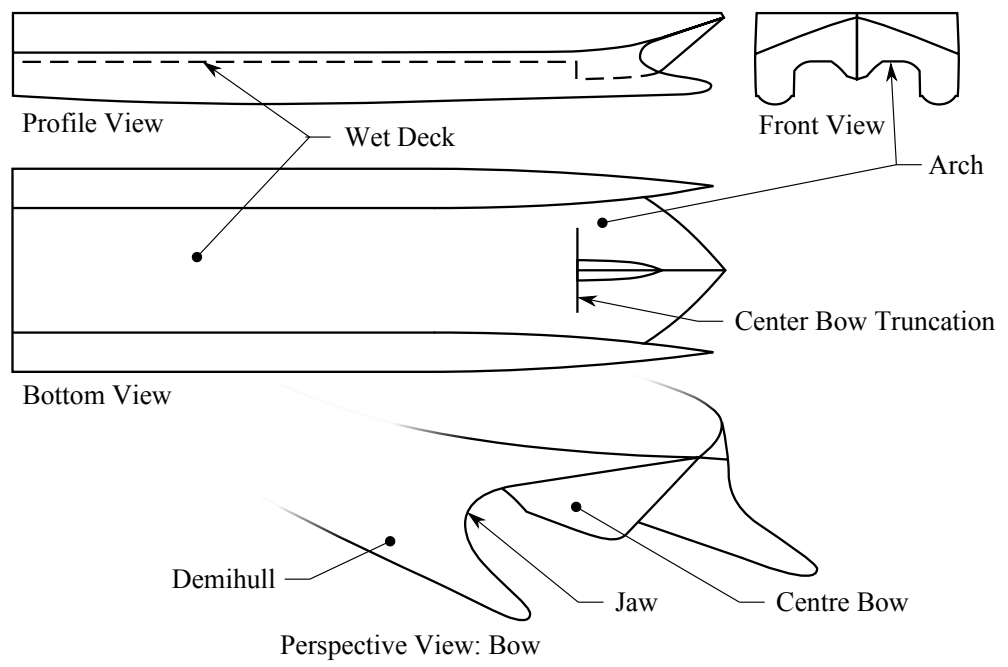

Figure 2: Geometric features of an Incat wave-piercing catamaran. 


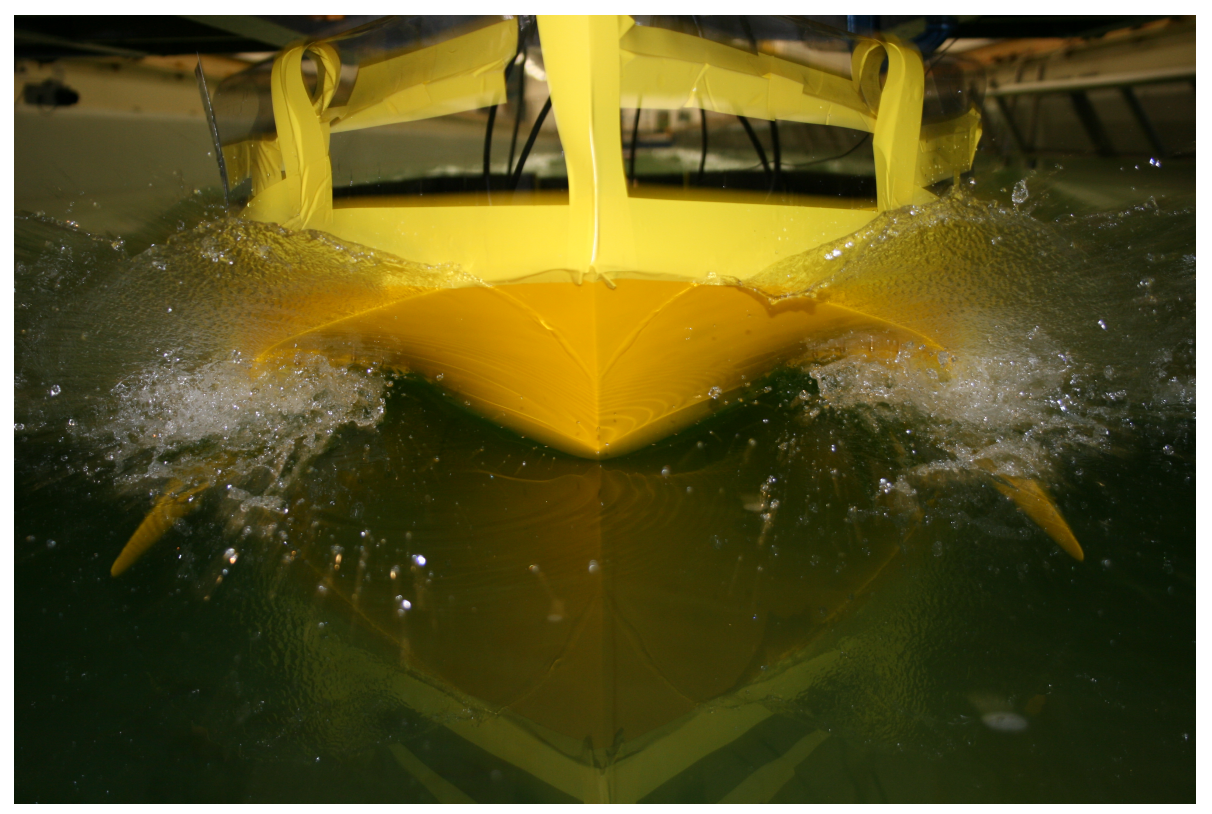

Figure 3: Flow field shortly after arch slam event on the hydroelastic segmented model tested by Lavroff [1] 


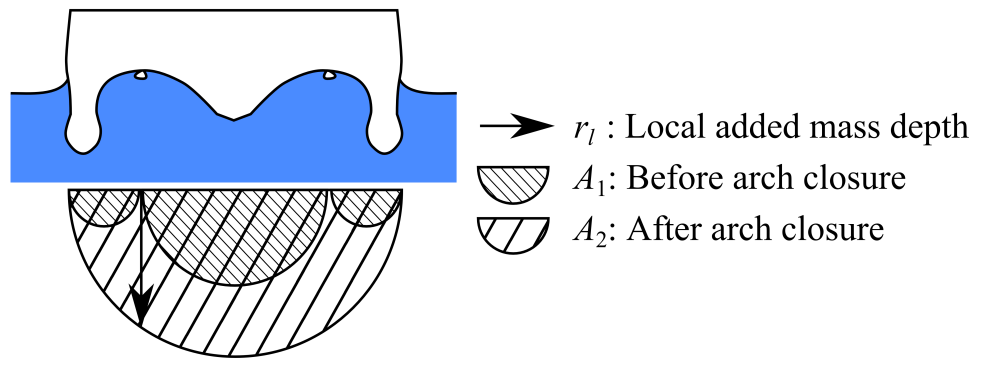

Figure 4: Sectional added mass before and after arch closure as determined on a sectional basis. 


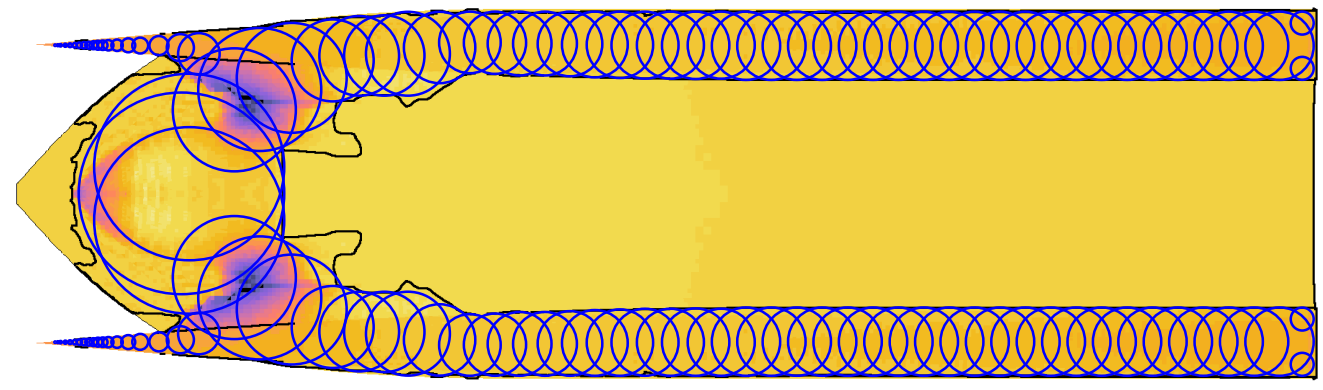

Wetted perimeter

Added mass representation

Figure 5: Illustrative example of using the horizontal plane radius to identify the radius to the nearest dry cell. For clarity, not all hemispherical fits are shown. In the implementation a radius is identified for every cell face. 
Meshed hull geometry

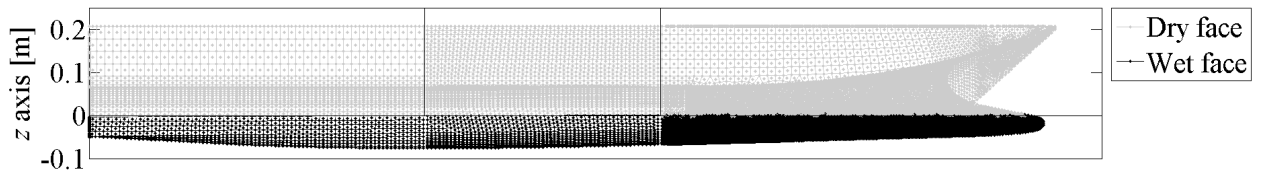

Added mass distribution

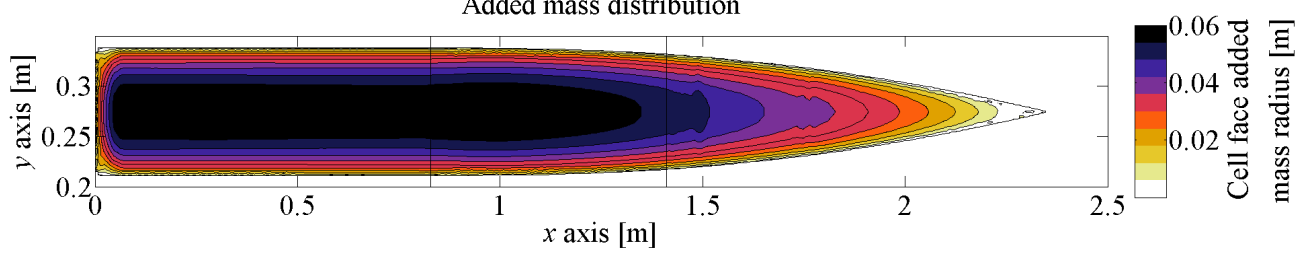

Figure 6: Calm water added mass distribution estimated using a hemispherical added mass distribution for a single demihull. The waterline is located at $z=0$. 


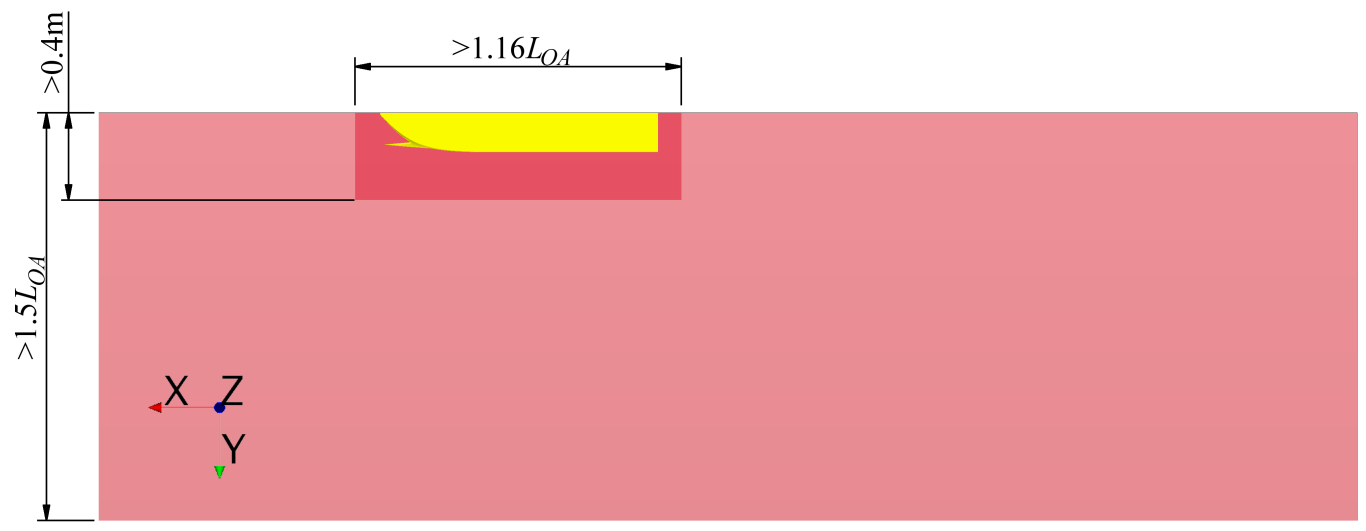

Plan View

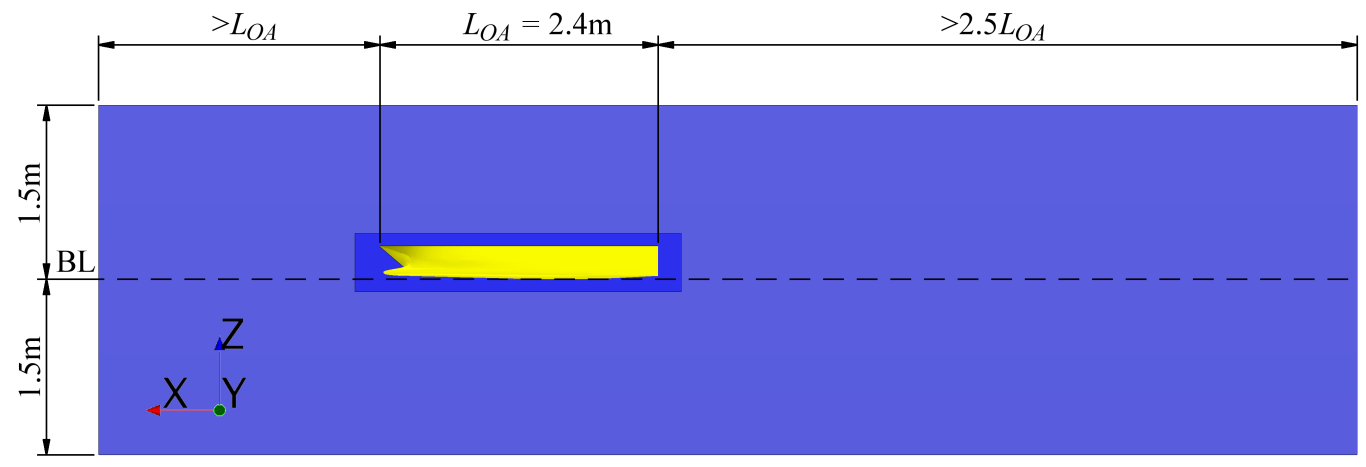

Profile View

Figure 7: Domain boundary locations relative to the wave piercing catamaran hull for simulation of motions and slamming loads in head seas. 
Primary free surface refinement

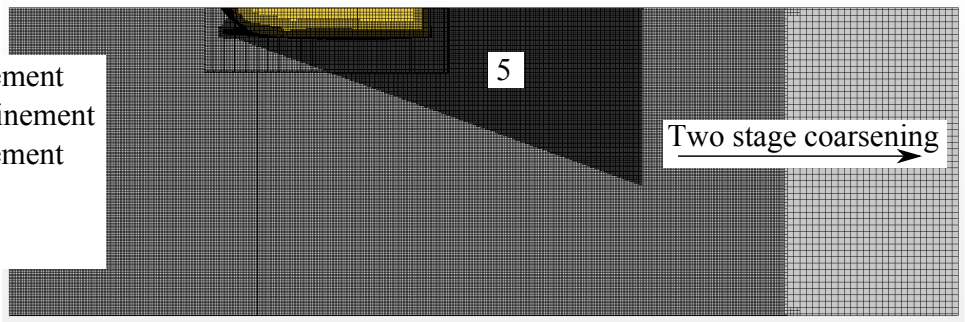

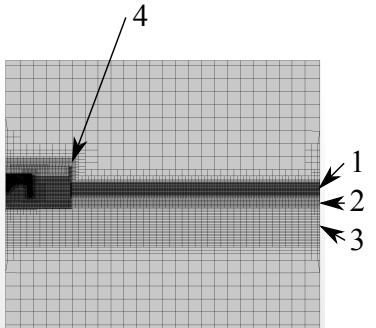

End View
Top View

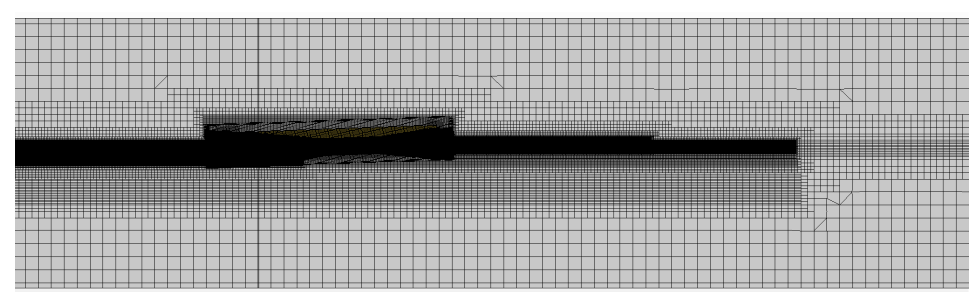

Side View

Figure 8: CFD domain mesh overview. The fine mesh from the grid dependence study is depicted. 


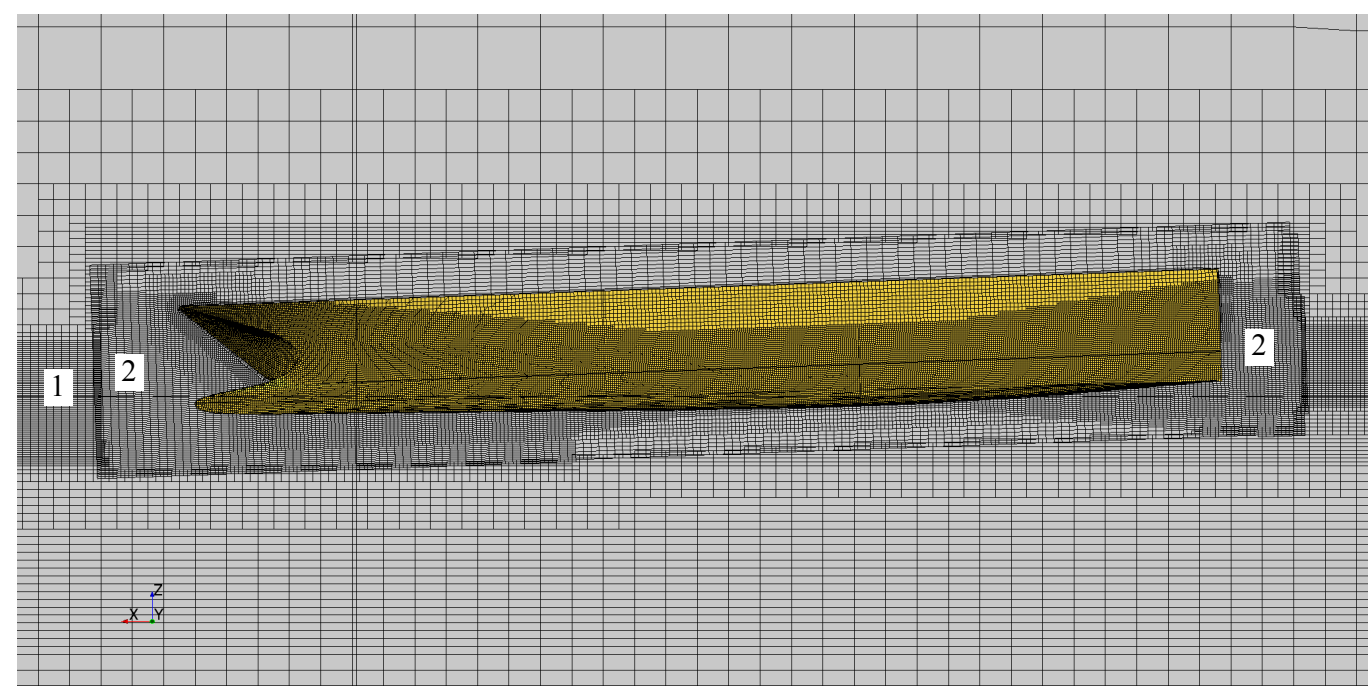

1. Primary free surface refinement extended further below free surface over forward third of hull and forward of hull to the inlet boundary

2. Wedge refinement zones on overset region to ensure free surface remains within primary refinement zone

Figure 9: Near hull CFD mesh. The fine mesh from the grid dependence study is depicted. 


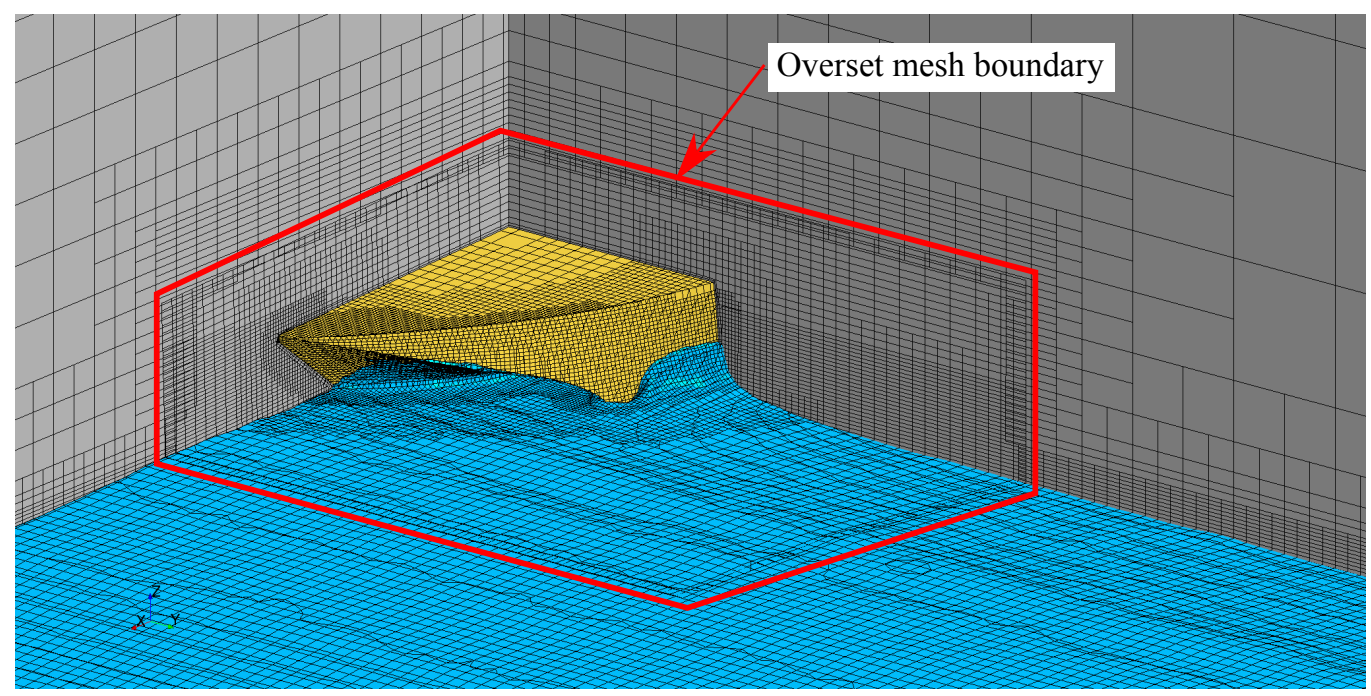

Figure 10: Isometric view of the bow region including free surface. The fine mesh from the grid dependence study is depicted. 


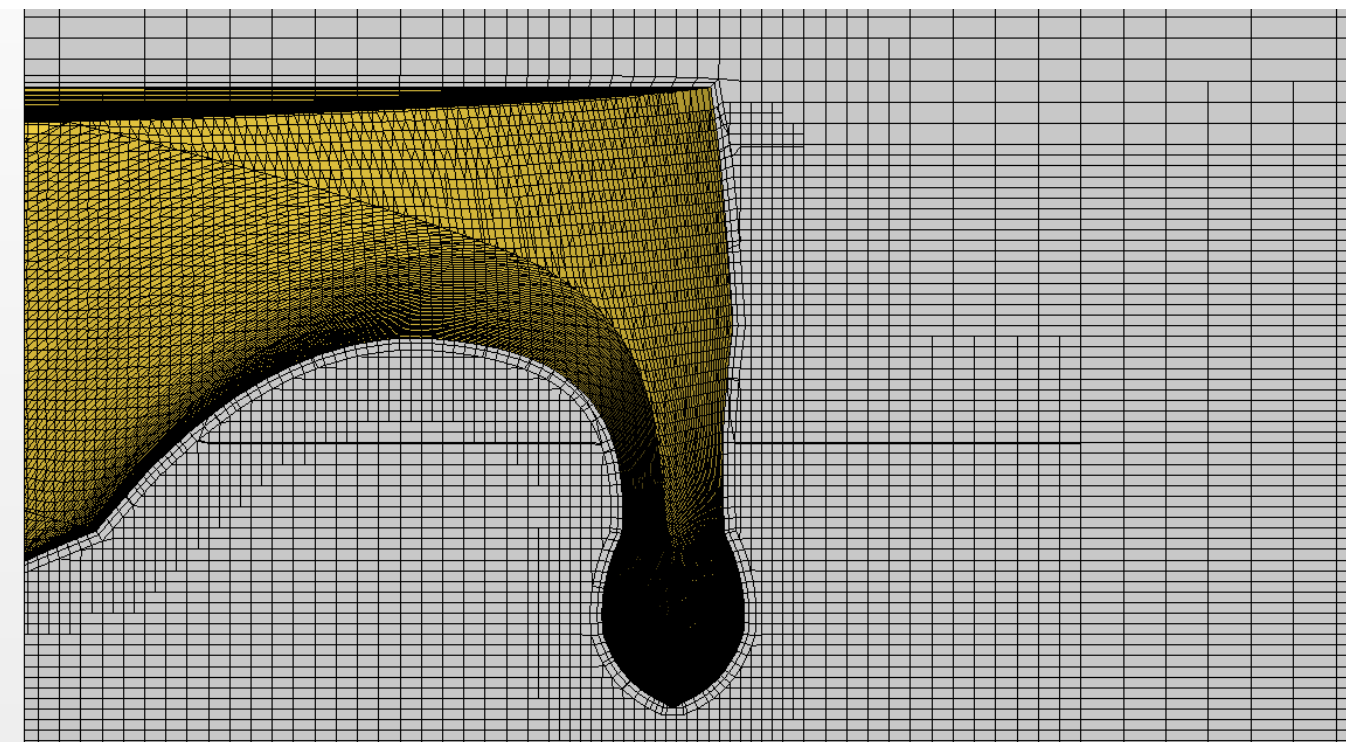

Figure 11: Transverse cross-section view of mesh taken at frame 74 (1.982 $\mathrm{m}$ from transom). The hull surface mesh overlaid on the cross-section view. The fine mesh from the grid dependence study is depicted. 


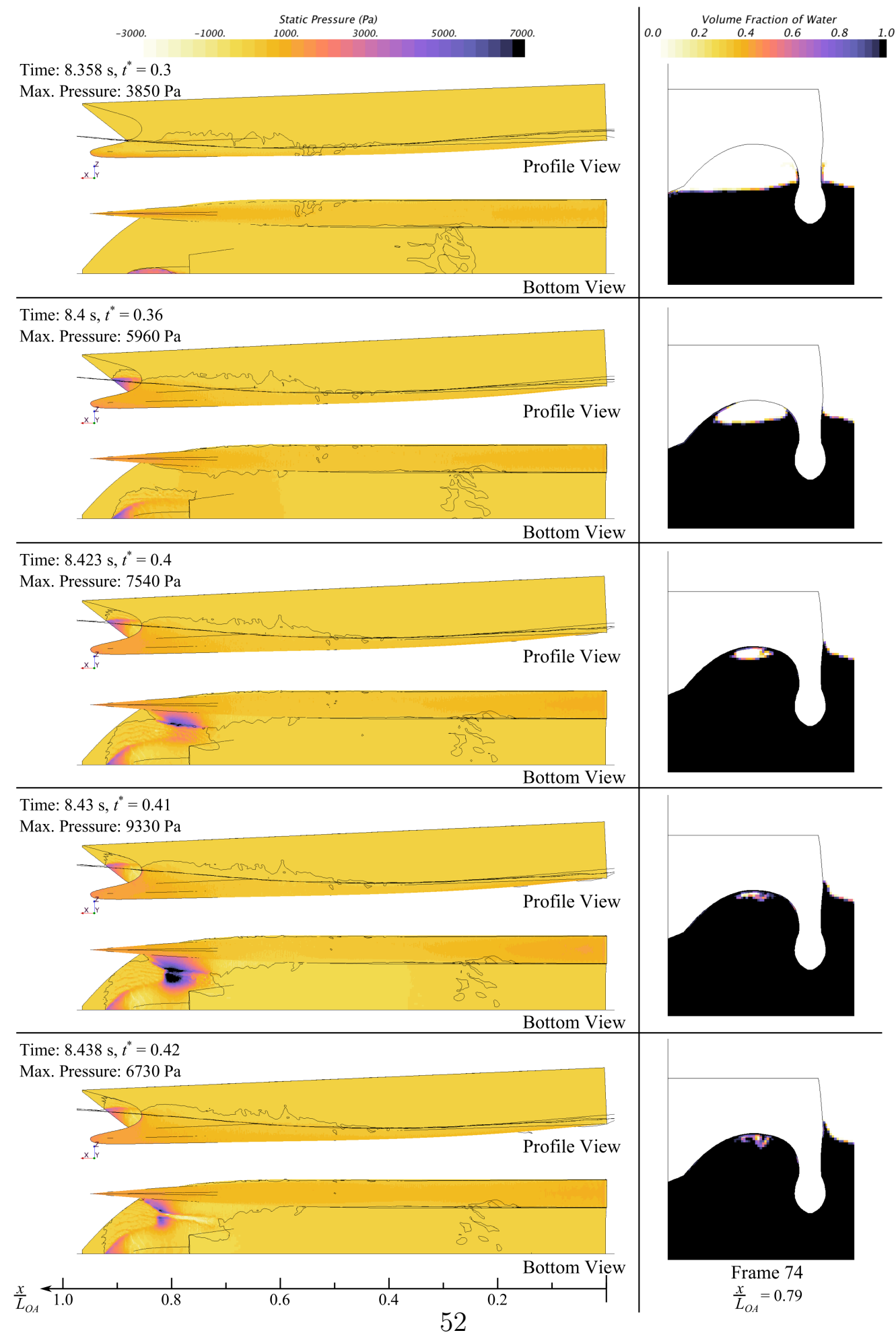

Figure 12: Pressure distribution acting in the arch region at several time instances during centre bow entry. 


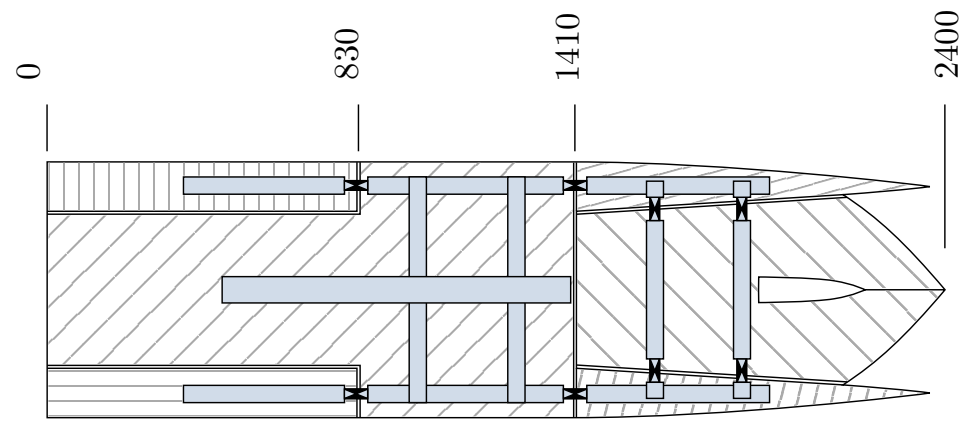

\begin{tabular}{l}
$\square \square$ 1. Aft Port Segment \\
\hline$\square$ 3. Aft Starboard Segment \\
\hline$\square$ 3. Mid Segment \\
$\square$ 5. Corward Port Segment \\
$\square /\|\backslash\|$ 6. Forward Starboard Segment \\
$\square$ 8. Aluminium Frame \\
8. Strain Gauge Half Bridge
\end{tabular}

Figure 13: Plan view schematic representation of the physical Hydroelastic Segmented Model showing the six individual segments. The links at the segment joints $1410 \mathrm{~mm}$ and $830 \mathrm{~mm}$ from the transom will be referred to as the forward and aft links respectively. 


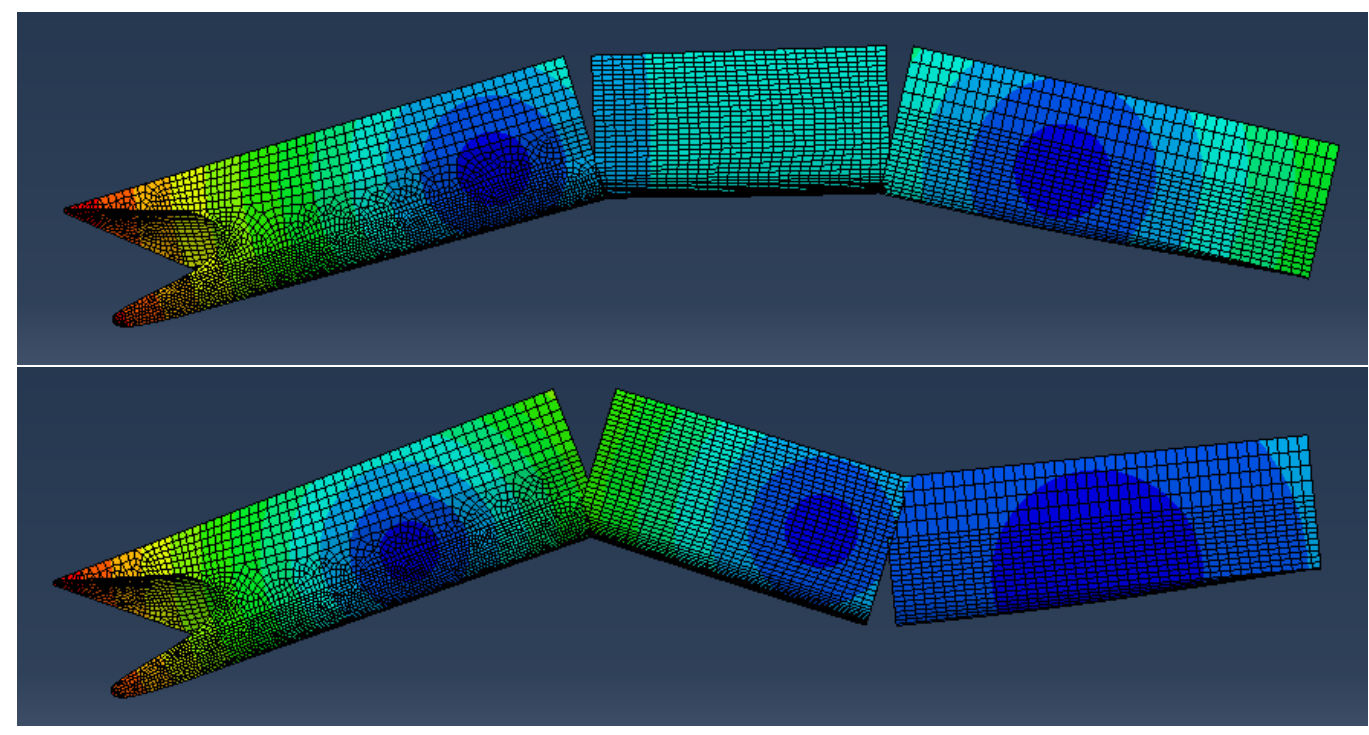

Figure 14: First (top) and second (bottom) bending modes of the finite element model in ABAQUS showing the generated structural domain surface mesh. (Note, the greatly exaggerated amplitudes of motion in the mode shape representation cause self intersecting geometry which does not occur in the transient simulations.) 


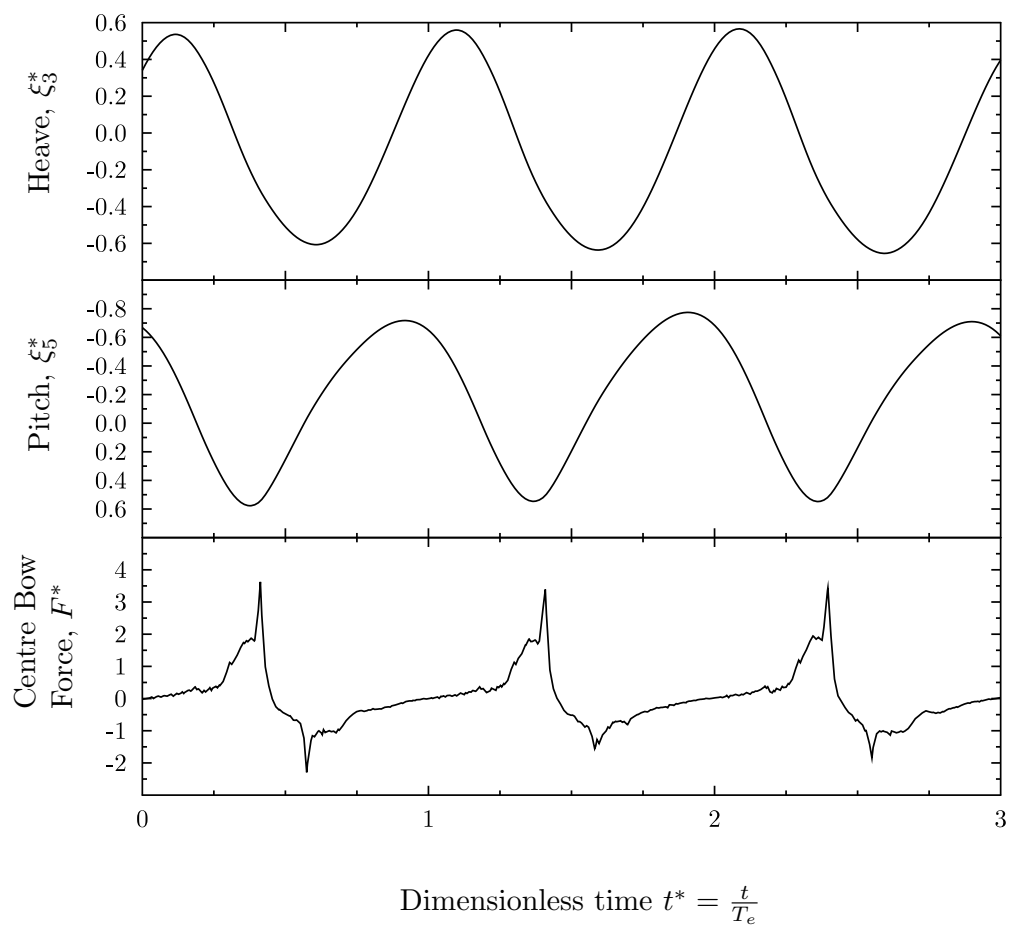

Figure 15: Example time varying motion and force records estimated using one-way interaction simulation for a dimensionless wave encounter frequency of $\omega_{e}^{*}=4.869$, a forward speed of $2.89 \mathrm{~m} / \mathrm{s}$ and a wave height of $90 \mathrm{~mm}$. 

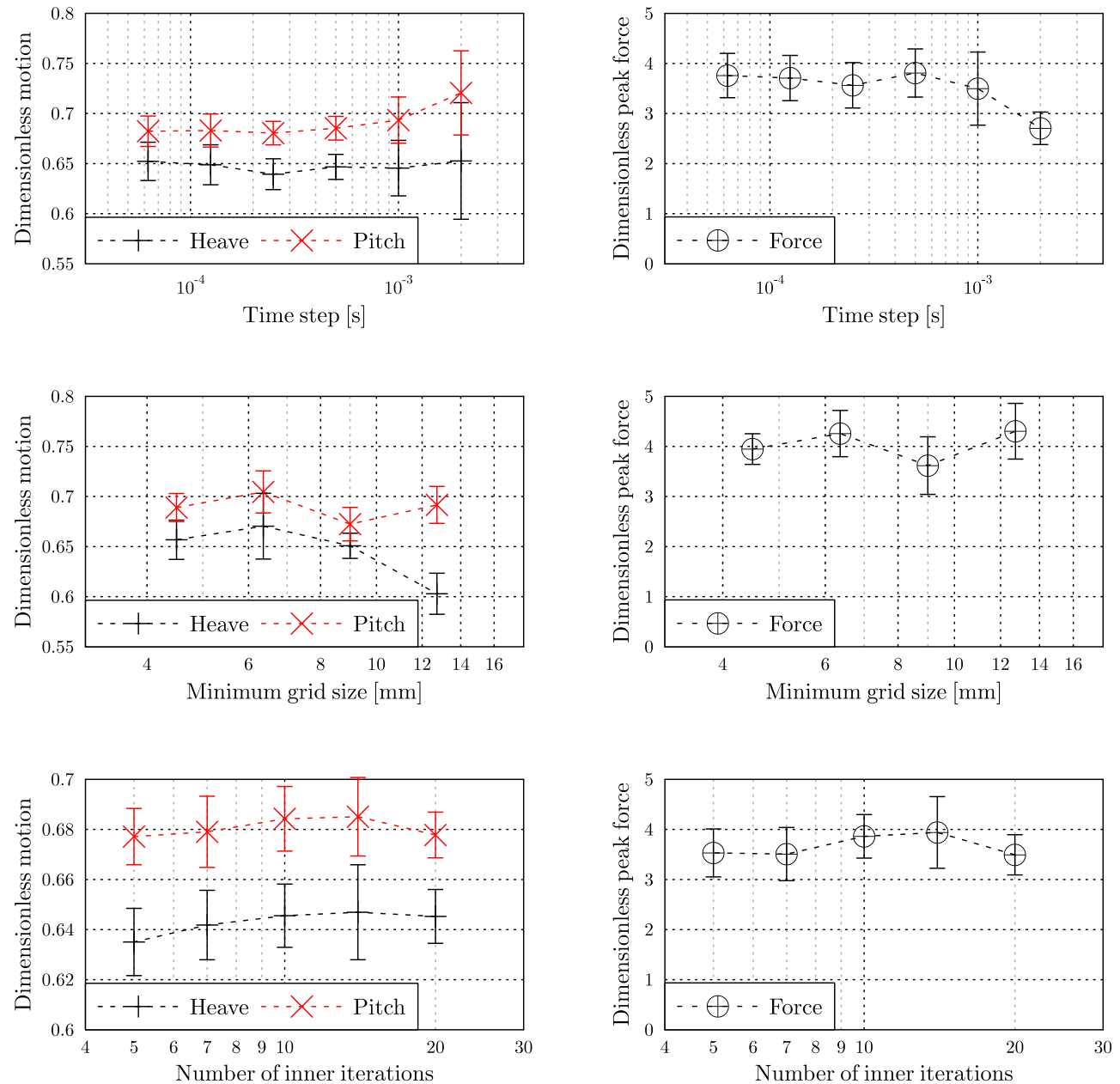

Figure 16: Convergence plots for solution dependence on grid, time step and number of iterations per time step. Error bars show plus and minus one standard deviation of the statistical variation between wave encounters in peak-to-peak amplitude. 

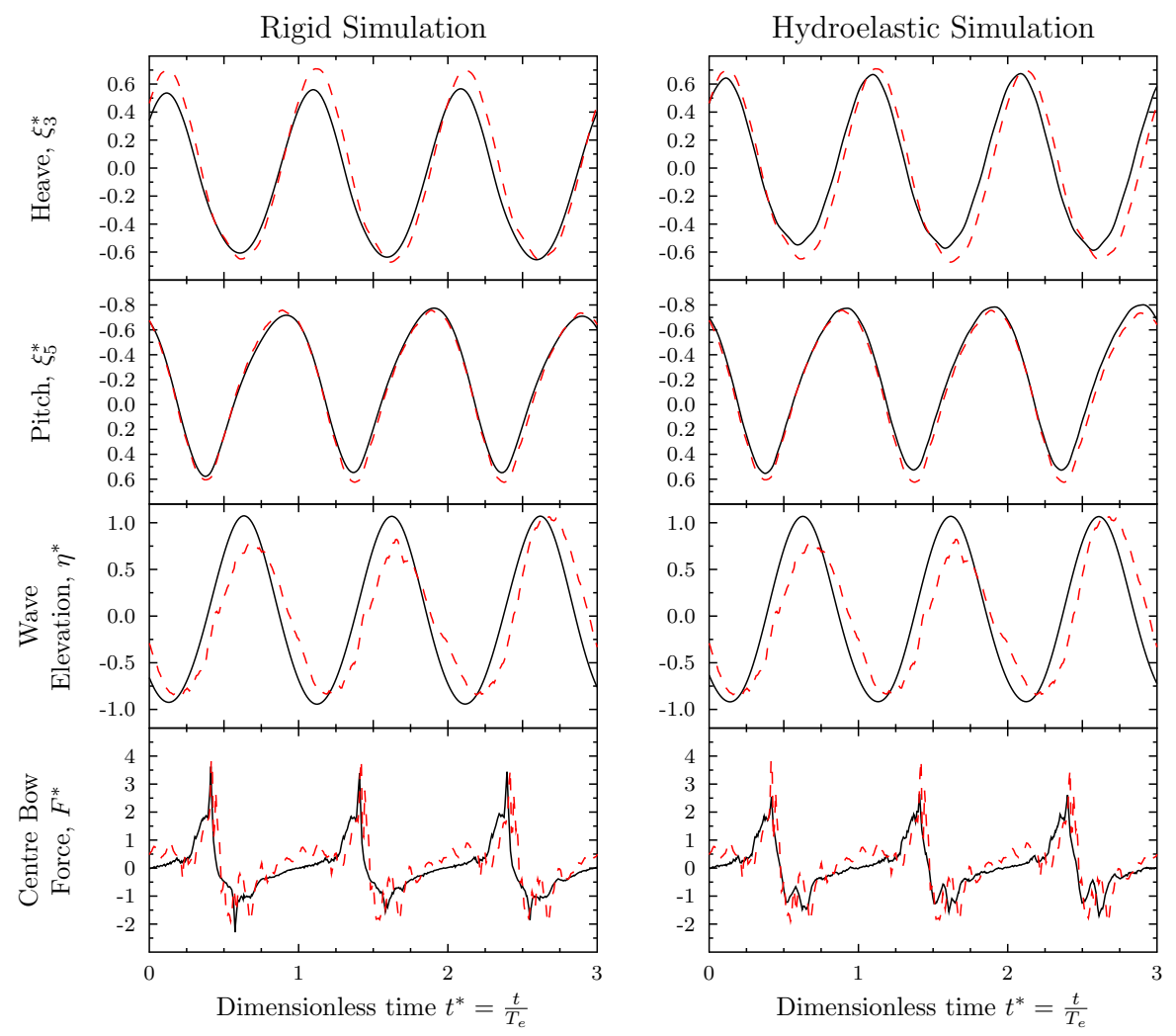

Simulation - - - Experiment

Figure 17: Dimensionless motion of rigid body simulation (left) and hydroelastic simulation (right) compared to experimental records for a dimensionless wave encounter frequency of $\omega_{e}^{*}=4.869$, a forward speed of $2.89 \mathrm{~m} / \mathrm{s}$ and a wave height of $90 \mathrm{~mm}$. The centre bow force has been included to allow the time of peak slam force to be identified in the records. 

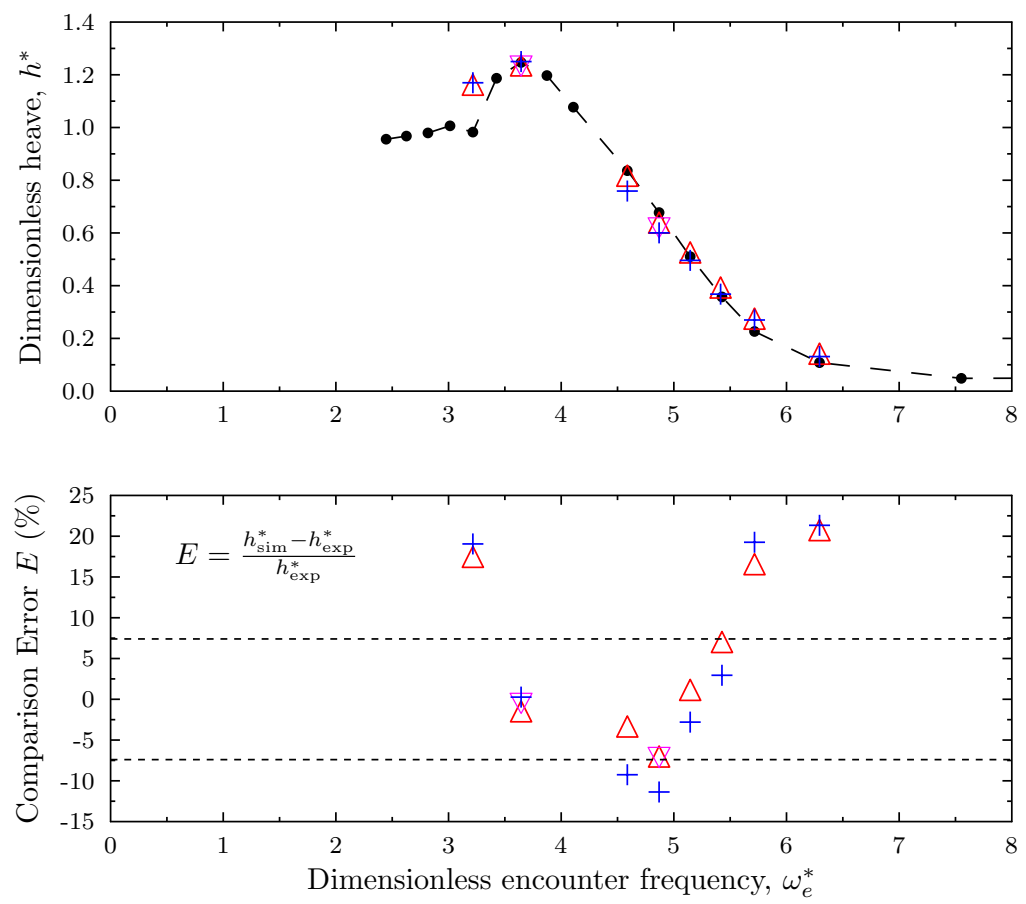

$\begin{array}{cl}-\bullet- & \text { Experiment (Lavroff, 2009) } \\ \triangle & \text { Two-way FSI: directly measured parameters } \\ \nabla & \text { Two-way FSI: modally inferred parameters } \\ + & \text { Star-ccm }+ \text {, rigid } \\ -\cdots & \text { Validation Uncertainty } \pm U_{V}\end{array}$

Figure 18: Simulated and experimental dimensionless heave response for a forward speed of $2.89 \mathrm{~m} / \mathrm{s}$ and a wave height of $90 \mathrm{~mm}$. 

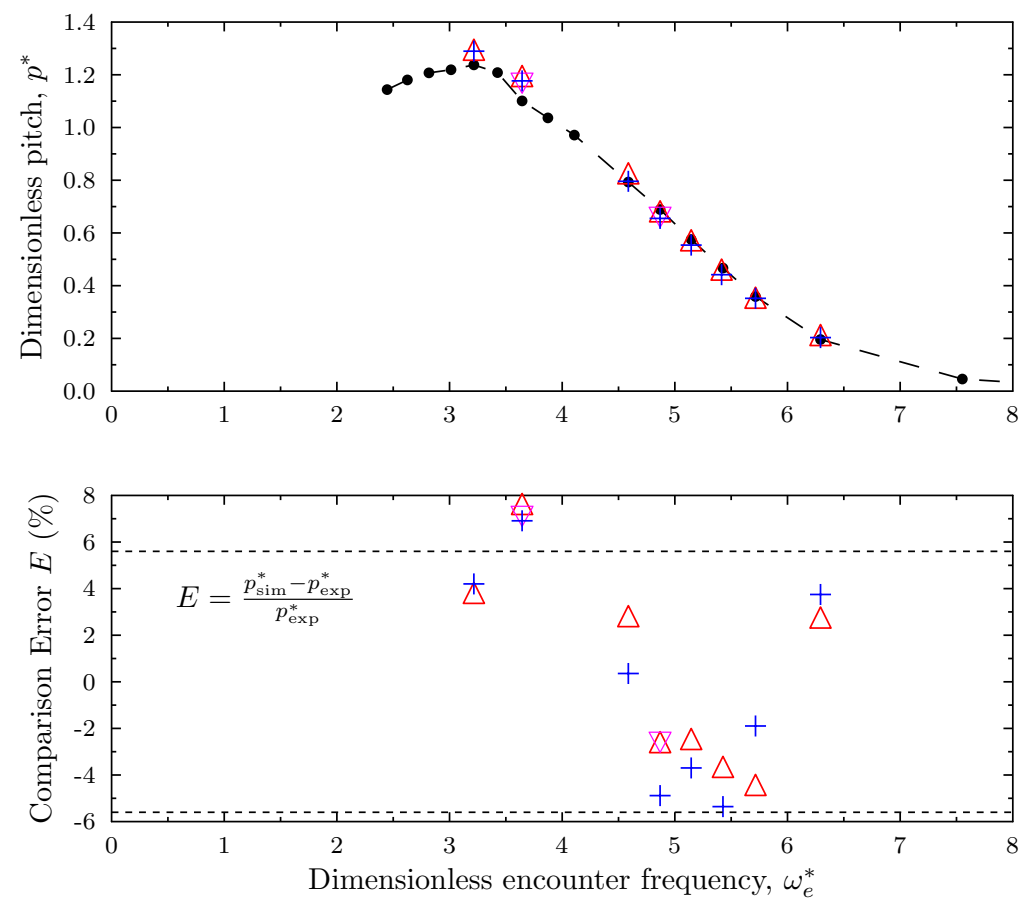

$\begin{array}{cl}-\bullet- & \text { Experiment (Lavroff, 2009) } \\ \triangle & \text { Two-way FSI: directly measured parameters } \\ \nabla & \text { Two-way FSI: modally inferred parameters } \\ + & \text { Star-ccm }+ \text {, rigid } \\ --- \text {. } & \text { Validation Uncertainty } \pm U_{V}\end{array}$

Figure 19: Simulated and experimental dimensionless pitch response for a forward speed of $2.89 \mathrm{~m} / \mathrm{s}$ and a wave height of $90 \mathrm{~mm}$. 
Forward Link

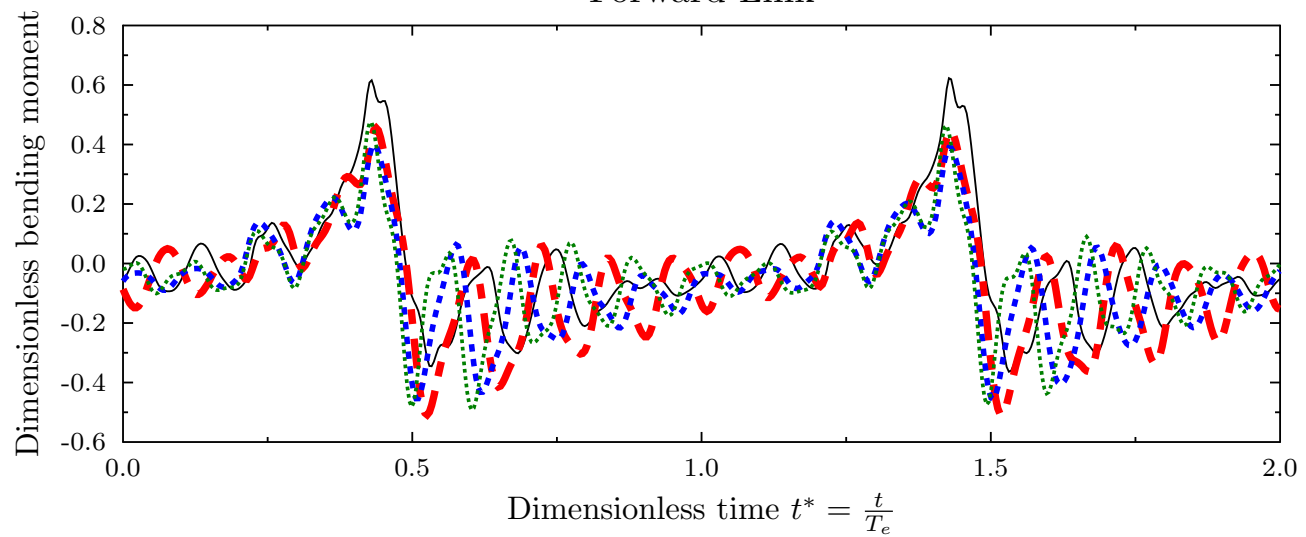

Aft Link

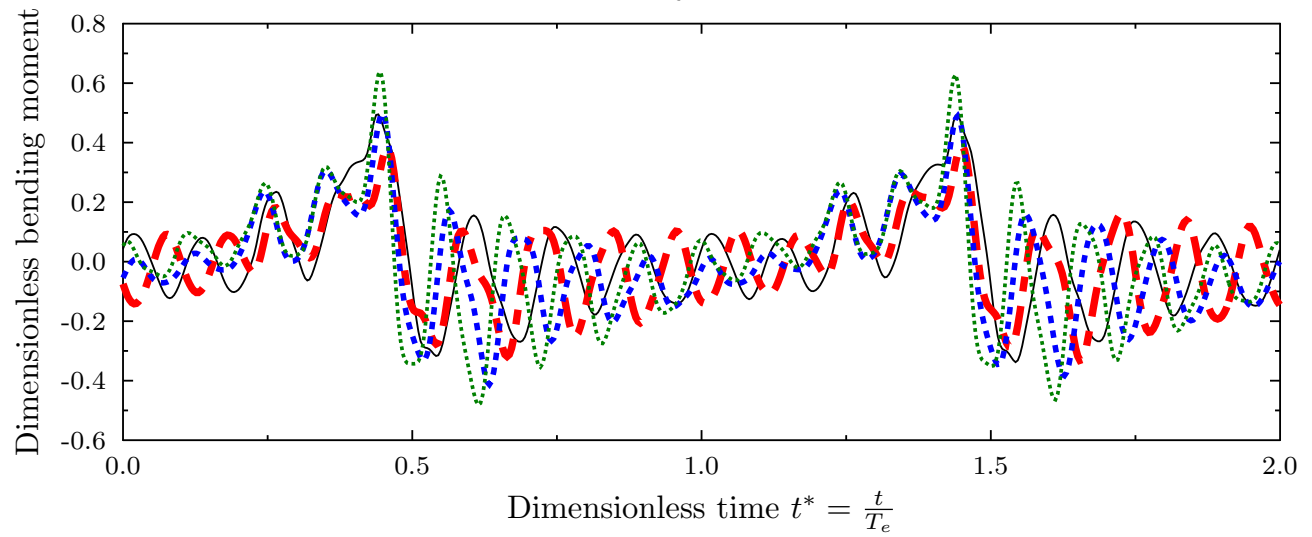

Experimental

- - - Two-way interaction simulation

........ One-way interaction simulation (variable added mass)

............... One-way interaction simulation (constant added mass)

Figure 20: Time domain bending response as measured experimentally compared to that predicted through: two-way interaction simulation, one-way interaction simulation with time varying added mass and one-way interaction simulation with constant added mass. The condition presented is for a dimensionless wave encounter frequency of $\omega_{e}^{*}=4.869$ at a forward speed of $2.89 \mathrm{~m} / \mathrm{s}$ and a wave height of $90 \mathrm{~mm}$. 


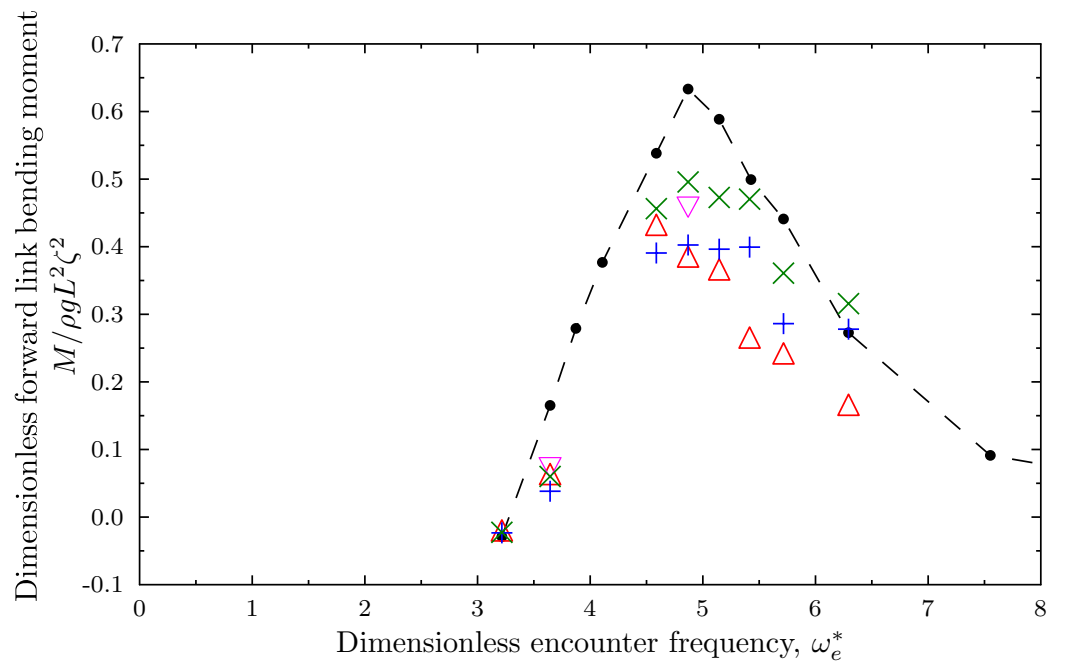

Forward Segment Link

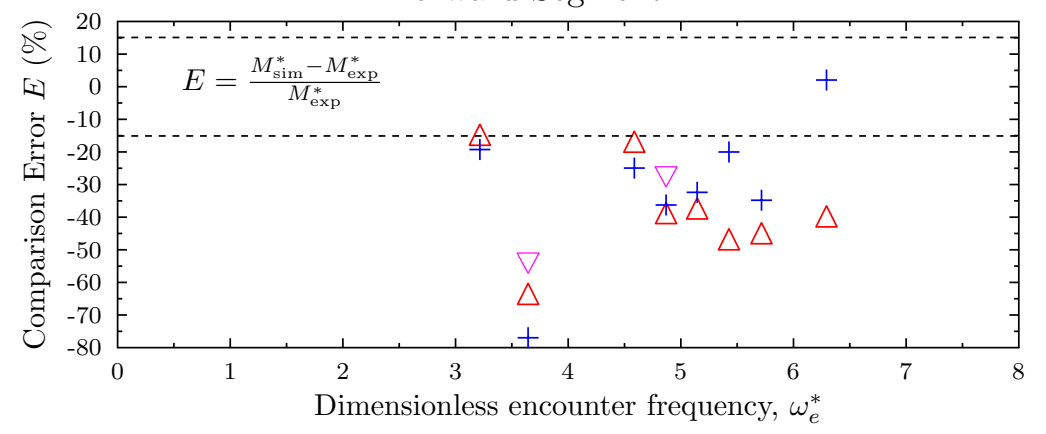

\begin{tabular}{|cl|}
\hline$-\bullet-$ & Experiment (Lavroff, 2009) \\
$\triangle$ & Two-way FSI: directly measured parameters \\
$\nabla$ & Two-way FSI: modally inferred parameters \\
+ & One-way FSI: variable added bow mass \\
$\times$ & One-way FSI: constant added bow mass \\
\hline
\end{tabular}

Figure 21: Simulated and experimental dimensionless bending moment at the forward and aft segment joins for a forward speed of $2.89 \mathrm{~m} / \mathrm{s}$ and a wave height of $90 \mathrm{~mm}$. 


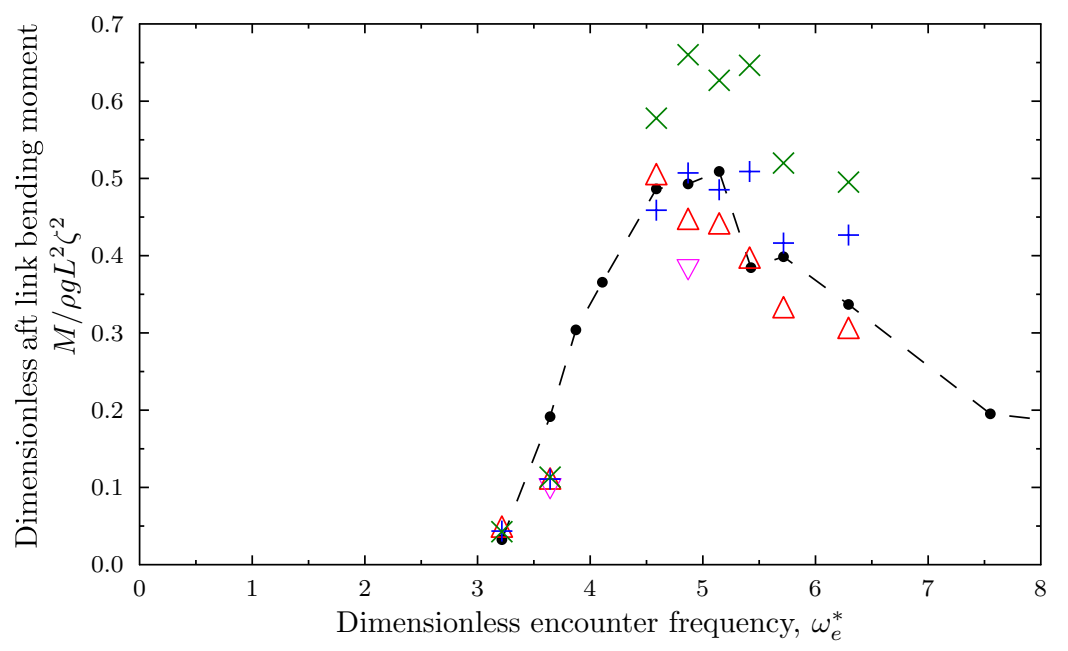

Aft Segment Link

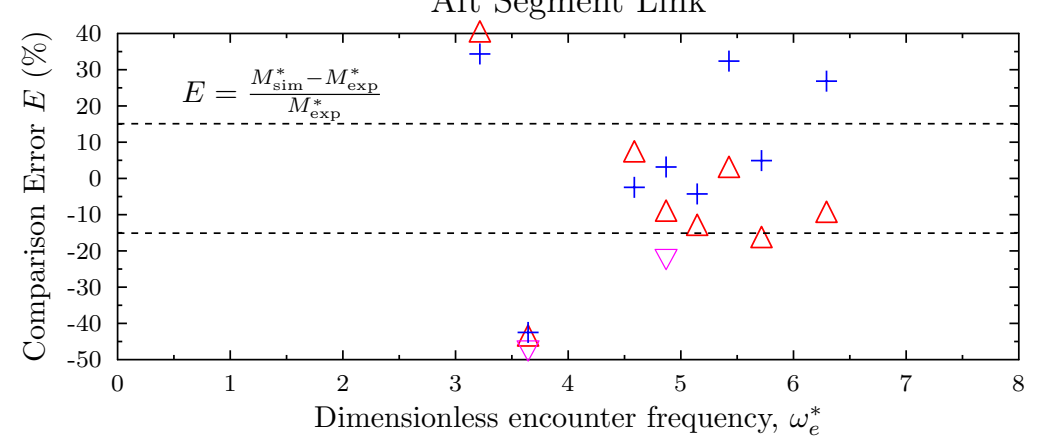

\begin{tabular}{|cl}
\hline$-\bullet-$ & Experiment (Lavroff, 2009) \\
$\triangle$ & Two-way FSI: directly measured parameters \\
$\nabla$ & Two-way FSI: modally inferred parameters \\
+ & One-way FSI: variable added bow mass \\
$\times$ & One-way FSI: constant added bow mass \\
\hline
\end{tabular}

Figure 22: Simulated and experimental dimensionless bending moment at the aft segment join for a forward speed of $2.89 \mathrm{~m} / \mathrm{s}$ and a wave height of $90 \mathrm{~mm}$. 


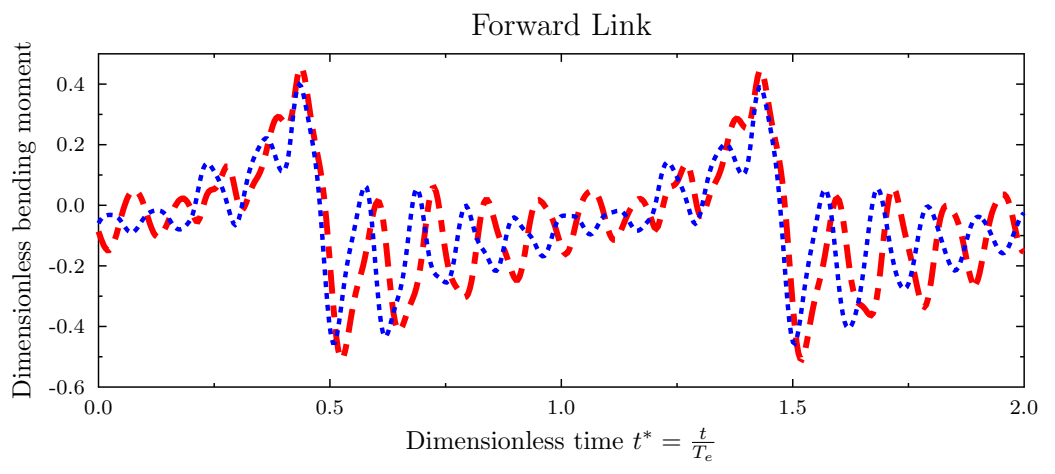

- - Two-way interaction simulation

....... One-way interaction simulation (variable added mass)

Figure 23: Transient bending moment at the forward link as predicted by two-way interaction and one-way interaction with added mass. 